\title{
Aprendizajes para las políticas e intervenciones sociales de discapacidad mental. El caso del Servicio de Capacitación Cecap, Toledo, España*
}

\section{Lessons for Policies and Social Interventions on Mental Disabilities. The Case of Training Service Cecap, Toledo, Spain}

\section{Aprendizagens para as políticas e intervenções sociais de discapacidade mental. 0 caso do Serviço de Capacitação Cecap, Toledo, Espanha}

Fecha de recepción: 28-05-14 Fecha de aceptación: 22-09-14 Disponible en línea: 01-07-14

doi: 10.11144/Javeriana.rgyps13-27.apis

Cómo citar este artículo:

Guzmán CA, Martínez A, Arancibia S, Molina V, Meseguer ML. Aprendizajes para las políticas e intervenciones sociales de discapacidad mental. El caso del Servicio de Capacitación Cecap, Toledo, España. Rev. Gerenc. Polít. Salud. 2014; 13(27): 96-127. http://dx.doi.org/10.11144/Javeriana.rgyps13-27.apis

\author{
Carlos Andrade-Guzmán** \\ Andrés Martínez-Medina*** \\ Sara Arancibia-Carvajal $* * * *$ \\ Valentín Molina-Moreno***** \\ María Leticia Meseguer-Santamaría******
}

Artículo de investigación. Las instituciones que financiaron el trabajo fueron: la Universidad de Castilla La Mancha (UCLM) y el Banco Santander, a través de su programa de becas de ayuda para estancias de investigación de profesores iberoamericanos en España, y el Servicio de Capacitación (Cecap) Toledo, España.

** Magíster en Gestión y Políticas Públicas de la Universidad de Chile. Profesor del Magíster en Gestión y Políticas Públicas de la Universidad de Chile y del Departamento de Trabajo Social de la Universidad Alberto Hurtado de Chile. Correo electrónico: candradeguzman@ing.uchile.cl. Dirección de correspondencia: Oficinas del Magíster en Gestión y Políticas Públicas de la Universidad de Chile. Calle Domeyko 2313, comuna de Santiago, Chile. Universidad de Chile. Departamento de Ingeniería Industrial.

*** Licenciado en Psicología Clínica por la Universidad Complutense de Madrid, especialista en especificidad y presidente del grupo de entidades sociales Cecap. Correo electrónico: cecaptoledo@gmail.com

**** Doctora en Ciencias Empresariales de la Universidad Autónoma de Madrid, directora del Instituto de Ciencias Básicas de la Facultad de Ingeniería de la Universidad Diego Portales de Chile, y profesora en diversos posgrados del Departamento de Ingeniería Industrial de la Universidad de Chile. Correo electrónico: sara.arancibia@udp.cl

****** Doctor en Ciencias Empresariales, profesor titular de la Universidad de Granada en el Departamento de Organización de Empresas. Actualmente dirige el Observatorio de Estudio de la Especificidad de la Universidad de Granada.

$96 \quad$ Correo electrónico: vmolina2@ugr.es Facultad de Ciencias Económicas y Empresariales de Albacete. Correo electrónico: MLeticia.Meseguer@uclm.es 


\section{Resumen}

Objetivos: recoger aprendizajes conceptuales para las iniciativas de discapacidad mental y determinar qué elementos metodológicos de intervención contribuyen mayormente a la inclusión del colectivo. Materiales y métodos: investigación centrada en el caso de Cecap, Toledo-España. ${ }^{1}$ Integró herramientas cualitativas (revisión documental y entrevistas a, entre otros, sujetos de intervención) y cuantitativas (AHP datos estudiados con análisis de contenido y estadística. Resultados: la "especificidad" que orienta conceptual y metodológicamente la intervención de Cecap, dialogando con la CIF-OMS, el modelo social y el enfoque de derechos, entiende al colectivo como personas con características específicas y diferenciadas, al igual que personas sin discapacidad. Metodológicamente, trabajar desde planes individuales de intervención, tiene la mayor prioridad para la inclusión. Conclusiones: las políticas e intervenciones debiesen considerar instrumentos que reconozcan las características e intereses específicos de los sujetos como capitales pro inclusión.

Palabras clave: políticas e intervenciones sociales en discapacidad mental; discapacidad; especificidad; intervención; derechos; elementos de intervención prioritarios para la inclusión social de sujetos con discapacidad mental

\section{Abstract}

Objectives: Collecting conceptual lessons for the initiatives on mental disabilities and determining what methodological interventions elements contribute the most to the inclusion of the group. Materials and Methods: Research focused on the Cacap case, Toledo, Spain ${ }^{2}$. We integrated qualitative tools (review of documentation and interviews performed to intervention subjects, among others), and quantitative tools (AHP), data studied with content analysis. Results: the "specificity" that conceptually and methodologically guides the intervention of Cecap, in dialogue with the CIF-OMs, the social model and the rights approach, understands the group as people with specific and differentiated characteristics, exactly as people without disabilities. Methodologically, working from individual intervention plans has the top priority for inclusion. Conclusions: The policies and interventions should consider instruments that acknowledge the specific characteristics and interests of the subjects as of utmost importance for inclusion.

Keywords: social policies and interventions on mental disabilities; disability; specificity; intervention; rights; priority intervention elements for social inclusion of subjects with mental disability

\section{Resumo}

Objetivos: Coligir aprendizagens conceituais para as iniciativas de discapacidade mental e determinar quais elementos metodológicos de intervenção contribuem maiormente para a inclusão do coletivo. Materiais e métodos: pesquisa centrada no caso de Cecap, Toledo-Espanha. ${ }^{3}$ Integrou ferramentas qualitativas (revisão documental e entrevistas a, entre outros, sujeitos de intervenção) e quantitativas (AHP), dados estudados com análise de conteúdo. Resultados: a "especificidade" que orienta conceitual e metodologicamente a intervenção de Cecap, dialogando com a CIF-OMS, o modelo social e o enfoque de direitos, entende o coletivo como pessoas com características específicas e diferenciadas, ao igual que pessoas sem discapacidade. Metodologicamente, trabalhar desde planos individuais de intervenção tem a maior prioridade para a inclusão. Conclusões: as políticas e intervenções deveriam considerar instrumentos que reconhecessem as características e interesses específicos dos sujeitos como capitais para a inclusão.

*Em português não existe o termo discapacidade mas deficiência, embora usa-se discapacidade para conservar o significado do termo em espanhol e evitar as implicações da deficiência ser inerente à pessoa e a discapacidade ser construída socialmente.

Palavras-chave: políticas e intervenções sociais em discapacidade mental; discapacidade; deficiência; especificidade; intervenção; direitos; elementos de intervenção prioritários para a inclusão social de sujeitos com discapacidade mental

1 Para profundizar en la experiencia de Cecap, véanse los siguientes sitios: www.cecaptoledo.es, www.ceca pjoven.es y www.futurvalia.com

2 To provide more insight on the Cecap experience, see the following websites www.cecaptoledo.es, www cecapjoven.es and www.futurvalia.com

3 Para aprofundar na experiência de Cecap, conferir os seguintes sites: www.cecaptoledo.es, www.cecapjoven es e www.futurvalia.com 


\section{Introducción}

La sociedad europea ha avanzado progresivamente en el desarrollo de políticas sociales que apunten a la inclusión social de diversos colectivos que se encuentran en situación de vulnerabilidad y exclusión. En este contexto, y particularmente en torno a la acción dirigida hacia las personas con discapacidad, la Estrategia Europea sobre Discapacidad 2010-2020: Un compromiso renovado para una Europa sin barreras (1), es un ejemplo del esfuerzo de las acciones desarrolladas por generar un marco que oriente las iniciativas que buscan la protección, el resguardo y la restitución de los derechos de las personas que presentan algún tipo de discapacidad.

Dicha estrategia dialoga en sus sentidos con instrumentos internacionales, como la propia Convención sobre los Derechos de las personas con discapacidad de Naciones Unidas del año 2006 (2) —en adelante, llamada indistintamente como la Convención-, así como también presenta un correlato con el Plan de acción para las personas con discapacidad 2006-2015 (3) del Consejo de Europa inspirado en dicha Convención, expresando la intención de las administraciones de los Estados por avanzar en el robustecimiento de las condiciones que apunten a la inclusión social de las personas con discapacidad, desde un enfoque centrado en el ejercicio de sus derechos.

En este sentido, los cambios que en alguna medida se han generado en los ordenamientos institucionales de los países en los últimos años, han incorporado, en términos generales, la adecuación de las políticas públicas, las leyes y las diversas intervenciones orientadas hacia el colectivo, buscando adscribir a los lineamientos que entrega la Convención y su protocolo facultativo.
Particularmente en el caso de España, el país ha avanzado a lo largo del tiempo en materia legislativa, robusteciendo su ordenamiento en torno a instrumentos que apunten a la inclusión social de las personas con discapacidad. Actualmente, es relevante mencionar el Real Decreto Legislativo 1/2013, del 29 de noviembre (4), por el que se aprueba el texto que conforma la Ley General de derechos de las personas con discapacidad y aborda su inclusión social, la cual en su artículo $1 \stackrel{0}{ }$ indica que sus objetivos, son primero el "garantizar el derecho a la igualdad de oportunidades y de trato, así como el ejercicio real y efectivo de derechos por parte de las personas con discapacidad en igualdad de condiciones respecto del resto de ciudadanos y ciudadanas, a través de la promoción de la autonomía personal, de la accesibilidad universal, del acceso al empleo, de la inclusión en la comunidad y la vida independiente y de la erradicación de toda forma de discriminación", así como también indica como objetivo el "establecer el régimen de infracciones y sanciones que garantizan las condiciones básicas en materia de igualdad de oportunidades, no discriminación y accesibilidad universal de las personas con discapacidad"1 (4).

Por su parte, a nivel de otros avances en materia de políticas públicas, se encuentran, así como la creación y/o refuerzo de diferentes organismos en materia de discapacidad, como el Servicio de Información sobre disca-

1 Esta ley explicita una disposición derogatoria única en términos normativos que deroga disposiciones de igual o inferior rango que se opongan a lo dispuesto en su texto refundido, y en particular, por integrarse en dicho texto refundido: la Ley 13/1982, de 7 de abril, de integración social de las personas con discapacidad; la Ley 51/2003, de 2 de diciembre, de igualdad de oportunidades, no discriminación y accesibilidad universal de las personas con discapacidad y la Ley 49/2007, de 26 de diciembre, por la que se establece el régimen de infracciones y sanciones en materia de igualdad de oportunidades, no discriminación y accesibilidad universal de las personas con discapacidad. 
pacidad (SID) $)^{2}$ o el Observatorio Estatal de la Discapacidad, ${ }^{3}$ el impulso de medidas como la Estrategia Española sobre Discapacidad 2012-2020 (5), la cual se inspira en los principios de la Convención y profundiza en el nivel de aplicabilidad de estos.

Cabe mencionar que en el marco de la adecuación permanente a los principios que promueve la Convención y, en especial, en pos de los desafíos que implica generar las condiciones para el pleno ejercicio de los derechos de las personas con discapacidad, diversa documentación especializada pone de relieve la necesidad de innovar de manera permanente en las intervenciones y políticas que se orientan a la plena inclusión del colectivo de personas con discapacidad. En esta línea se inscriben las menciones de la Estrategia Española sobre Discapacidad 2010-2020 (5), la Recomendación número 5 del Plan de acción para las personas con Discapacidad 2006- 2015 (6), o los postulados de la propia Ley General de derechos de las personas con discapacidad y de su inclusión social (4).

En este marco, cabe señalar que desde una mirada enfocada en los diferentes tipos de discapacidad: mental, intelectual, física o sensorial, la literatura especializada ha señalado los mayores niveles de vulnerabilidad a los que se enfrentan quienes cuentan con un diagnóstico vinculado a discapacidad mental o intelectual. Al respecto, la Organización Mundial de la Salud —en adelante, llamada indistintamente como la oMs- (7), en su informe mundial sobre la discapacidad del año 2011, ha señalado que "las personas que sufren problemas de salud mental o deficiencias intelectuales parecen ser las que presentan las mayores desventajas en muchos ámbitos, en

2 Véase: http://sid.usal.es/default.aspx

3 Revísese: http://www.observatoriodeladiscapacidad.es/ comparación con las que poseen deficiencias físicas o sensoriales" (7, p. 9).

Estos elementos, a su vez, han sido planteados por Acuña, Bulit, Chudnovsky y Repetto (8) quienes han argumentado que, incluso en interior del colectivo amplio de personas con discapacidad, aquellas con discapacidad mental o intelectual pueden, en ocasiones, enfrentar situaciones de exclusión mayor que aquellas con discapacidad, por ejemplo, física o sensorial. Señalan que "no es extraño escuchar demandas de políticas inclusivas para un tipo de discapacidad (por ejemplo, contar con rampas y facilidades de acceso y movilidad para PCD con discapacidad motriz) que van acompañadas por el silencio, la ignorancia o la desconfianza hacia la inclusión de otro tipo de discapacidades (por ejemplo, la incorporación de las PCD intelectuales o mentales a los ámbitos educativos comunes)" (8, pp. 37-38).

Lo anterior dialoga con elementos planteados por Anaut-Bravo, Urizarna y Verdugo (9), quienes han señalado que las personas afectadas por una discapacidad mental se sienten mayormente discriminadas en comparación con personas, por ejemplo, con discapacidad física (9), elementos que permiten observar la necesidad que se configura en torno a pensar en las condiciones que es preciso generar y/o reforzar para contribuir a una plena inclusión social que posibilite el ejercicio activo de derechos del colectivo de personas con discapacidad mental, escenario en el cual la mirada permanente a las iniciativas de intervención desde una reflexión situada en el cómo innovar y recoger aprendizajes tanto en los sentidos como en las prácticas de las prestaciones, se vuelve relevante en pos de esta contribución hacia una plena inclusión.

En este contexto, los elementos expuestos configuran el problema de investigación que 
aborda este trabajo. Lo anterior, desde la relevancia atribuida a la necesidad de innovación de manera permanente de las iniciativas que se orientan a la población con discapacidad mental, en tanto de acuerdo con lo señalado por la evidencia internacional, conforman dentro del colectivo de personas con discapacidad, a las que pueden ser reconocidas como mayormente vulnerables $(7,8)$.

En este escenario, se pone de relieve la necesidad de recoger aprendizajes para las iniciativas de política e intervención en discapacidad mental, particularmente desde su relevancia para la inclusión social.

Así, desde un mirada centrada en la contribución a la plena inclusión del colectivo en un marco de derechos, el presente trabajo buscar dar respuesta, por un lado, a qué aprendizajes conceptuales pueden levantarse para las políticas e intervenciones sociales de discapacidad mental. Por otro, desde una mirada centrada en aspectos metodológicos de intervención, busca responder qué elementos componentes y subcomponentes presentes en diseños de intervención pueden generar una mayor contribución a la plena inclusión social de quienes presentan discapacidad mental.

Así, en dialogo con estas interrogantes, se plantea como objetivos el recoger aprendizajes conceptuales para las iniciativas y determinar qué elementos metodológicos de intervención contribuyen en mayor medida a la inclusión del colectivo.

Lo anterior, situándose desde una perspectiva de derechos humanos. Ello, en tanto reconociendo que la comprensión del fenómeno de la discapacidad desde este marco, le asigna una principal relevancia a los aspectos medioambientales como elementos relevantes para la mayor o menor inclusión social, posibilita configurar el componente de justificación del problema de investigación, el cual orientado por elementos de relevancia social, contribuye al campo de conocimiento desde los aportes que pueden realizarse en términos de observar dispositivos que provean aprendizajes tanto conceptuales como metodológicos que puedan iluminar las políticas e intervenciones que apuntan a la plena inclusión de sujetos con discapacidad mental.

Así, inscribiéndose en esta problemática, este trabajo se apoya en la revisión exhaustiva del caso del Servicio de Capacitación-Cecap Toledo, de la comunidad de Castilla-La Mancha - en adelante, llamado indistintamente como Cecap o como la entidad-. Se ha seleccionado esta experiencia, en tanto se han reconocido en ella elementos innovadores de hacer intervención con el colectivo, como por ejemplo, la utilización de espacios normalizados de forma permanente durante la prestación, entre otros que se exponen a lo largo de este documento y que dejan de lado miradas centradas en la institucionalización del colectivo.

Cabe precisar que este trabajo no incorpora dentro de sus objetivos el hacer un análisis comparativo de experiencias de intervención, sino que más bien persigue, desde la revisión en profundidad de este caso, reconocer aprendizajes que puedan aportar a la innovación de las políticas e intervenciones sociales de discapacidad mental. Así, se abre una puerta de inicio para revisar con la misma profundidad otras experiencias en desarrollo que permitan reconocer elementos para la innovación permanente de la acción desarrollada en pos de la inclusión del colectivo, desde una mirada que enfatice en el ejercicio activo de sus derechos.

Tomando como base estos antecedentes, el presente trabajo se estructura en seis secciones. La primera, constituida por esta introducción; una segunda, en la cual se presenta el marco metodológico del trabajo; 
la tercera, en la cual se realiza una revisión de los modelos que históricamente han orientado las acciones dirigidas hacia las personas con discapacidad; la cuarta, en la cual se presentan los resultados del trabajo situados desde la experiencia de Cecap. La quinta, en la que se someten a discusión los resultados, analizándolos a la luz de la literatura especializada en discapacidad y derechos y, finalmente, la sexta sección, en la que se presentan las principales conclusiones en términos de aprendizajes para las políticas e intervenciones sociales de discapacidad mental surgidas a la luz de este trabajo.

\section{Metodología}

\section{Tipo de estudio}

Este trabajo ha buscado dar respuesta a las preguntas de investigación que lo han movilizado, a través de la integración de herramientas cualitativas y cuantitativas en el marco de un estudio de tipo exploratoriodescriptivo. Lo anterior, desde el análisis situado en el caso de Cecap. En este contexto, su vertiente exploratoria se inscribe en que el estudio en búsqueda de aprendizajes para las políticas e intervenciones en el campo específico de las iniciativas orientadas a sujetos con discapacidad mental, se advierte como un campo relativamente poco estudiado, respecto a otras iniciativas orientadas a colectivos vulnerables.

Por su parte, su eje descriptivo se sostiene en el hecho de que en el marco de esta recolección de aprendizajes, se ha buscado hacer una descripción en profundidad de aquellos elementos que pueden servir para iluminar las iniciativas de política e intervención que promueven la inclusión del colectivo.

\section{Primer momento: subestudio cualitativo}

En un primer momento, se ha llevado a cabo un subestudio de tipo cualitativo, el que se ha sostenido sobre dos vertientes: la revisión documental y el desarrollo de entrevistas en profundidad a informantes claves.

En torno a la investigación documental, Valles (10) plantea que "la expresión más característica de esta opción metodológica se encuentra en los trabajos basados en documentos recogidos de archivos (oficiales o privados); documentos de todo tipo, cuya elaboración y supervivencia (depósito) no ha estado presidida, necesariamente, por objetivos de investigación social” (10, p. 109). En este contexto, en tanto estudio situado en la experiencia de Cecap, los documentos revisados fueron seleccionados con base en un criterio de inclusión que obedecía a elementos de muestreo intencionado por criterios, el cual radicó en el que se inscribieran en documentos técnicos que dieran cuenta de los elementos específicos del diseño y la implementación de la intervención de la entidad, específicamente revisando dos documentos: dossier (11) y protocolo de actuación (12). ${ }^{4}$

Por su parte, en relación con el levantamiento de datos con base en entrevistas en profundidad, se realizaron 14 instancias de indagación, distribuidas en formatos individuales y grupales. En este contexto, individualmente, se realizaron seis entrevistas con sujetos de intervención, tres con directores de unidad, y una con un representante del servicio de atención a personas con discapacidad, de la Consejería de Salud y Bienestar Social de la Junta de Comunidades de Castilla-La Mancha.

4 Véanse las referencias bibliográficas de este trabajo. 
A su vez, en términos de las entrevistas grupales realizadas, fueron llevadas a cabo cuatro: una con cuatro sujetos de intervención, una con cinco asesores metodológicos de intervención, una con ocho familiares o adultos responsables $\mathrm{y}$, finalmente, una con dos representantes de organizaciones con las cuales se desarrolla la intervención en los territorios, permitiendo en suma recoger la percepción de veintinueve actores claves vinculados a la intervención de la entidad, en el marco de diez indagaciones individuales y cuatro grupales.

Con respecto a los criterios de elegibilidad para la participación en las instancias, estos fueron diferenciados en función del segmento estructural de representación del informante. Así, en relación con los sujetos de intervención, se priorizó el que fueran mayores de edad; el que llevasen más de un año participando de la intervención; el que hubiesen participado previamente de intervenciones situadas en modelos alternativos con características más bien centradas, en términos generales, en el modelo médico rehabilitante; y el que contasen con capacidad de expresión y un nivel de funcionalidad que les posibilitase participar de la experiencia.

En torno a los familiares o adultos responsables, el que el sujeto con quien estuviese vinculado formase parte de la intervención por más de un año y que hubiese participado de experiencias previas situadas en mayor medida en el enfoque médico; el que se contase con la tutela del sujeto; y el que fuesen familiares o adultos responsables de sujetos que no hubiesen participado de las entrevistas individuales o grupales.

Por su parte, en relación con los informantes de organizaciones colaboradoras, se priorizó el que fuesen colaboradoras por más de un año de Cecap o haber participado como mínimo en dos ciclos continuados de menor tiempo.
En relación con los directores de unidad y asesores metodológicos, participaron dado su conocimiento técnico de la intervención. Finalmente, el representante del servicio de atención a personas con discapacidad, de la Consejería, fue convocado a participar de las entrevistas, dado su conocimiento de la intervención de Cecap, y el que podía aportar con una mirada comparativa de la oferta de servicios de intervención.

Cabe relevar que tanto la revisión documental como las entrevistas se orientaron por una matriz de operacionalización de variables, que buscó indagar, por un lado, respecto al concepto de especificidad, específicamente sobre focos como la comprensión del concepto; sus principios constitutivos y las diferencias y similitudes de la noción de especificidad en relación con la de discapacidad; y por otro, sobre aspectos metodológicos de intervención, como por ejemplo, el funcionamiento de los componentes metodológicos transversales de intervención de Cecap, con independencia del ámbito específico del bienestar en el cual se sitúe la prestación (trabajo, educación u otros que se exponen en el tabla 1), las principales características de cada uno y sus desafíos y posibilidades en cuanto a inclusión social. ${ }^{5}$

Por su parte, en relación con formas de aplicación, los entrevistados fueron informados de los objetivos de la investigación y accedieron voluntariamente a participar de las entrevistas, para lo cual se les aseguró el anonimato.

Cabe precisar, a su vez, que dadas las especificidades de los sujetos de intervención, las preguntas de las pautas de entrevistas en este caso específico, siendo orientadas por la misma operacionalización de variables, se formularon tomando en consideración las adaptaciones necesarias en el lenguaje,

5 Entre otros que no se exponen en este trabajo. 
que facilitaran el que ellos pudiesen dar respuesta a las interrogantes, proceso de formulación en el que se contó con la asesoría de educadores diferenciales.

\section{Segundo momento: subestudio cualitativo y cuantitativo con AHP}

En un segundo momento, tomando como referencia los elementos recogidos con base en el estudio realizado con revisión documental y entrevistas, se procedió a realizar una indagación incorporando herramientas cualitativas y cuantitativas por medio de la aplicación de la metodología multicriterio proceso analítico jerárquico: AHP. ${ }^{6}$ Esta posibilitó modelar los componentes metodológicos de intervención de Cecap en una estructura jerárquica y determinar cuantitativamente las prioridades que cada uno de ellos tiene en el objetivo de inclusión social de sujetos con discapacidad mental.

Cabe relevar que, metodológicamente, el AHP se basa en el desarrollo de tres principios: la construcción de una estructura en donde se ordenan los elementos que es necesario considerar en el modelo; el establecimiento de prioridades, con base en matrices de comparaciones a pares (para lo cual se utiliza la escala de Saaty, permitiendo sintetizar los juicios del equipo de informantes); $y$, por último, la verificación de la consistencia de dichos juicios. A su vez, en relación con axiomática, esta herramienta se sostiene sobre el cumplimiento de cuatro específicos: reciprocidad, homogeneidad, dependencia y expectativas $(13,14)$.

En ese marco, este subestudio se desarrolló considerando la aplicación de seis entrevistas grupales con la participación de doce personas encargadas del diseño e implementación de la intervención de Cecap: directores de

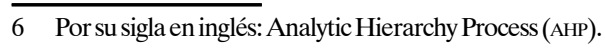

unidad, asesores metodológicos y agentes de intervención directa.

Se priorizó por este tipo de informantes en términos de muestreo por criterios, por contar con una visión que comprendía las posibilidades y tensiones que enfrenta el modelo a la hora de hablar de inclusión social y ejercicio de derechos.

En este sentido, este momento del levantamiento de datos se orientó por una operacionalización específica de variables que comprendía tres ejes generales: determinación de los subcomponentes específicos de intervención inscritos en cada componente transversal; comprensión conceptual de cada componente y subcomponente, y determinación de su prioridad en el objetivo de inclusión social.

Cabe relevar en torno a formas de aplicación, que de las seis entrevistas grupales, las dos primeras tuvieron características de aproximación exclusivamente cualitativa, en tanto se centraron en la determinación y comprensión conceptual de los elementos del modelo de intervención.

Con posterioridad, se pudieron ajustar los alcances conceptuales de cada elemento del modelo, discutidos en una nueva instancia grupal, de manera de calibrar los alcances de cada elemento - componentes y subcomponentes - del modelo y validar su ubicación en la estructura jerárquica.

Posteriormente, en las tres entrevistas grupales siguientes, se procedió a determinar las prioridades de cada elemento con el grupo de informantes aplicando AHP. Ello, en instancias diferenciadas que reconociesen las prioridades de los elementos conforme el nivel de la estructura en el que habían sido incorporados. 
Finalmente, en la sexta entrevista grupal se calibraron las prioridades del modelo haciendo una revisión completa en torno a sus alcances en materia de inclusión social del colectivo.

Cabe precisar, igualmente, que en cada una de las entrevistas grupales se recogieron las reflexiones que surgieron del ejercicio de construcción y determinación de prioridades del modelo, desde sus implicancias para la inclusión social de sujetos con discapacidad mental, y que en cada una de las instancias de indagación, los participantes fueron informados de los objetivos del estudio, marco en el cual accedieron a participar de las instancias de entrevistas.

\section{Técnica de análisis de los datos}

En ambos momentos - subestudios-, los datos fueron analizados utilizando como técnica el análisis de contenido cualitativo. Ello, tanto en un sentido cualitativo en la primera etapa (15), como en una integración de cualitativo y cuantitativo en el momento dos.

Particularmente, respecto al último momento, es preciso señalar que se utilizó tanto el análisis de contenido cualitativo, como las herramientas de la estadística descriptiva para estudiar los porcentajes de prioridad de cada elemento del modelo metodológico de intervención de Cecap en la inclusión social del colectivo.

Finalmente, se ha de poner de relieve que los datos en el marco del análisis cualitativo en ambos momentos, fueron revisados apoyándose en rejillas de contenido, mientras que los datos cuantitativos provenientes de AHP fueron estudiados apoyándose en el software Expert Choice.

\section{Modelos de discapacidad que han orientado históricamente las políticas e intervenciones sociales hacia el colectivo}

Las políticas e intervenciones en discapacidad mental han avanzado conforme lo han hecho los modelos con los cuales se ha comprendido a lo largo del tiempo el fenómeno. En este sentido, se reconoce la existencia de tres modelos principales en la materia: el modelo de la prescindencia, el modelo médico-rehabilitador, y el modelo social, los cuales se abordan a continuación.

\section{El modelo de la prescindencia}

El modelo de la prescindencia, que data de la Edad Media, asumía que los determinantes de la discapacidad radicaban en motivos religiosos, considerando a las personas con discapacidad como innecesarias. Ello, por diversas razones: una supuesta no contribución al desarrollo de la comunidad, explicada porque se les veía como portadores de mensajes diabólicos, o incluso, porque representaban la molestia o el castigo de los dioses $(16,17)$.

El denominador común del modelo es la consideración de la persona con discapacidad como "innecesaria" y, por tanto, prescindible por parte de la sociedad. Dentro de este modelo, es posible situar dos submodelos reconocidos a nivel internacional: el submodelo eugenésico y el submodelo de la marginación.

Palacios (16) plantea que esta subdivisión deriva de las consecuencias de la supuesta “innecesariedad” del colectivo. Así, respecto al submodelo eugenésico, la solución a la discapacidad era alcanzada por medio de la aplicación de este tipo de prácticas. A este respecto, en materia de infancia, por ejemplo, se instala la eliminación de los niños y las niñas que al momento de nacer presentaran 
alguna particularidad física o intelectual que se considerara como riesgosa, conforme al contexto histórico y cultural. Díaz (18), referenciando el trabajo de Barnes, señala que "el infanticidio de los niños considerados débiles al nacer, según diferentes autores, era bastante común. Con el surgimiento del darwinismo social en el siglo XIX, el movimiento eugenésico reapareció, fundamentando el antiguo mito en la racionalidad científica, y teniendo la consideración de que las personas con imperfecciones físicas o intelectuales suponían un peligro para la sociedad" $(18$, p. 88$)$.

En el segundo submodelo, por su parte, la forma de enfrentar la discapacidad se sostenía sobre prácticas de marginación: "La respuesta por parte de la sociedad fue excluyente y segregadora en su máxima expresión, se les institucionalizaba en forma permanente, conformándose así el submodelo de la marginación” (19, p. 39).

Un elemento característico de este submodelo es que prácticas como el infanticidio van quedando atrás, lo cual de acuerdo con Palacios (16) implicaba que muchos niños y niñas sin recursos económicos fallecieran por falta de la atención médica básica.

Díaz (18) expone que en este submodelo, las personas con discapacidad eran objeto de burla o diversión, o bien recibían el cuidado por parte de la beneficencia y la caridad.

Lo anterior da cuenta de una debilidad, en términos de un rol activo estatal en el abordaje y generación de condiciones desde las políticas sociales para la atención de las personas que presentaban alguna determinada discapacidad. Palacios (16) advierte que el destino de muchos niños y muchas niñas durante esta etapa era el ocupar un sitio entre los mendigos. Estas evidencias permiten reconocer que en el marco de este submodelo de la prescindencia, el rol de la sociedad civil, cristalizado en acciones de beneficencia, cumplía un papel determinante en el tipo de atenciones que podían recibir los niños y las niñas con alguna discapacidad.

\section{El modelo médico-rehabilitador}

En el marco de la medicina, este modelo comienza a instalarse a nivel internacional, entendiendo las causas de la discapacidad, ya no como consecuencia de tipo religioso, sino como dadas por condicionantes de salud.

Asimismo, la creencia de la "innecesariedad" desde este modelo, de acuerdo con Palacios (16), deja de ser predominante, considerando que las personas con discapacidad, pueden aportar al desarrollo social, en la medida en que sean "rehabilitados" o "normalizados".

En este contexto, las políticas e intervenciones sociales orientadas al colectivo presentan un énfasis en el componente de salud, en tanto se persigue la "cura" de determinada discapacidad presente en la persona.

A este respecto, la Organización Mundial de la Salud, a través de la Clasificación Internacional del Funcionamiento, de la Discapacidad y de la Salud (20) del año 2001 —en adelante, mencionada igualmente como la CIF-OMs- plantea que desde este modelo, "el tratamiento de la discapacidad está encaminado a conseguir la cura, o una mejor adaptación de la persona y un cambio de su conducta. La atención sanitaria se considera la cuestión primordial y en el ámbito político, la respuesta principal es la de modificar y reformar la política de atención a la salud" (20, p. 22).

En materia de niños y niñas con alguna discapacidad, Palacios (16) comparando este modelo con el de la prescindencia, expone que este representa para muchos niños y niñas una posibilidad de supervivencia 
mayor, como resultado de la aplicación de tratamientos médicos utilizados a fin de salvar sus vidas, como asimismo orientados a alcanzar su rehabilitación.

\section{El modelo social}

Un tercer modelo orientador de las políticas y de las intervenciones sociales en materia de discapacidad, es el que es conocido como el modelo social.

La CIF-OMs (20) plantea que este entiende el fenómeno fundamentalmente como un problema de origen social. La discapacidad no es entendida como un atributo de la persona, sino como un complicado conjunto de elementos, muchos creados por el entorno.

Así, este modelo concentra su atención en las características que presenta la sociedad, en términos de cómo facilita o dificulta el desenvolvimiento de las personas que presentan una discapacidad determinada. Así, de acuerdo con Martínez (17), este dirige su atención a los problemas que la sociedad tiene para absorber o incorporar las características diferentes de las personas con discapacidad. El problema así no se sitúa en la propia persona, ni es necesario afrontarlo de forma particular, sino que se reconoce como un problema común con soluciones colectivas.

Palacios (16) expone los presupuestos fundamentales que caracterizan al modelo social, relevando en primer lugar que, a diferencia de los otros modelos, en este la discapacidad no tiene su origen en condicionantes religiosas ni médicas (o científicas), sino que tiene sus explicaciones en aspectos mayoritariamente sociales, dados por el contexto particular en el cual se encuentran las personas con discapacidad. en este modelo las personas con discapacidad tienen, a lo menos, lo mismo que aportar a la sociedad que cualquier otra persona considerada como "sin discapacidad", y que dicho aporte presentará un correlato con el cómo una determinada sociedad acepte la diferencia con respecto a las características de las personas con discapacidad. Expone que partiendo de la premisa de que toda vida humana es igualmente digna, desde el modelo social se argumenta que lo que puedan aportar a la sociedad las personas con discapacidad se encuentra directamente relacionado con la inclusión y la aceptación de la diferencia.

Cabe poner de relieve que el modelo social es el que ha sido reconocido como aquel que orienta la propia Convención sobre los Derechos de las Personas con Discapacidad. En esta línea, Palacios (16) ha expuesto que la incorporación de este modelo en el espacio del derecho, puede ser comprendido desde la consideración de la discapacidad como un asunto de derechos humanos. Agrega, en este sentido, que la Convención representa un instrumento que se encuentra inspirado en una filosofía definida hacia el modelo social, lo que puede observarse en la gran mayoría de los artículos que la componen.

Así, específicamente desde los alcances conceptuales de lo que ha de entenderse por discapacidad desde un enfoque de derechos, la propia Convención reconoce en el concepto dos ejes anclas: la condición de salud y el carácter medioambiental que hoy día condiciona en una medida relevante el grado o nivel de discapacidad que podría presentar una persona. En esta línea, explicita en su preámbulo el que "la discapacidad es un concepto que evoluciona y que resulta de la interacción entre las personas con deficiencias y las barreras debidas a la actitud y al entorno que evitan su participación plena y efectiva en la sociedad, en igualdad de condiciones con las demás" (2), reconociendo, en este sentido, la relevancia de los elementos medioambien- 
tales en torno a la inclusión del colectivo, dialogando conforme lo que señala Palacios (16), con los alcances del modelo social.

En este sentido, desde una mirada centrada en la aplicación de este modelo específico, se reconoce el que este tensiona a los países a revisar su ordenamiento en pos de generar medidas que apunten a transversalizarlo y operativizarlo en las prestaciones que se orientan hacia el colectivo. En esta línea, Acuña, Bulit, Chudnovsky y Repetto (8) señalan que el modelo social de la discapacidad fuerza "a una revisión del entramado sociopolítico y de la economía política de las políticas públicas vinculadas directa e indirectamente a la temática de la discapacidad, de la normativa legal, de sus formas de aplicación concreta, de las acciones de los diferentes actores estatales y no estatales, y de los contextos institucionales en los que estas se desenvuelven" (8, p. 29).

De lo anterior se recoge que las políticas e intervenciones sociales que apunten hacia la plena inclusión social de las personas con discapacidad mental, deberán tener en consideración los lineamientos del modelo social de la discapacidad, en tanto, siguiendo a Palacios (16), pilar orientador de la Convención sobre los derechos de las personas con discapacidad. En este marco, lo anterior implicará la permanente revisión y búsqueda de aprendizajes para las iniciativas, de manera de repensar las acciones de política e intervención que mejor apunten a esta inclusión, en aras de un ejercicio efectivo de derechos por parte del colectivo.

Así, y desde una mirada centrada en lo que habrá de entenderse por plena inclusión de las personas con discapacidad mental desde un enfoque de derechos, con base en los elementos expuestos, en adelante se referirá a ella como aquel escenario en que toda persona con discapacidad mental puede, en igualdad de condiciones que las demás personas, con y sin discapacidad, hacer un ejercicio activo de sus derechos y libertades fundamentales, en los diferentes ámbitos de desarrollo o de bienestar.

\section{Análisis de resultados}

Presentación situada en el caso: intervención desde la especificidad en la oferta de Cecap

El Servicio de Capacitación (Cecap) nace el año 2006, trazándose el objetivo de mejorar la calidad de vida de las personas con discapacidad mental, a través de una oferta de prestaciones sociales que propendan por el rompimiento de los circuitos de exclusión, a los cuales, por su diagnóstico de salud, en determinados momentos, se han visto enfrentadas estas personas.

En esta línea, desarrolla su intervención como entidad en cuatro ámbitos específicos del bienestar: trabajo, educación, funcionalidad y ocio/tiempo libre, y vida independiente. Lo anterior, dependiendo del objetivo de inclusión de los sujetos a los cuales se orienta su accionar. ${ }^{7}$ En este sentido, una persona con discapacidad mental atendida puede ser sujeto de una intervención en un ámbito específico del bienestar, así como también, de una combinatoria de ellos, dependiendo de sus necesidades y características específicas.

En este contexto, en la tabla 1 se presentan, de manera sintética, los diferentes tipos de acciones desarrolladas por la entidad en estas cuatro dimensiones del bienestar.

$7 \quad$ En el marco de lo expuesto, para efectos de este trabajo se hablará de "el objetivo de inclusión", con independencia de que en algunos casos una persona sea sujeto de diversas prestaciones en un mismo ámbito o de una combinación de ámbitos de intervención, como puede ser el caso de un sujeto para y con el cual se trabaja, por ejemplo, desde prestaciones del ámbito de Vida Independiente y del ámbito de Trabajo. 
TABLA 1. INTERVENCIONES POR ÁMBito QUe CONFORMAN LA OFERTA de CECAP

\begin{tabular}{|c|c|c|}
\hline Ámbito del bienestar & Tipos de prestación & Beneficiarios \\
\hline Educación & $\begin{array}{l}\text { a) Capacitación orientada a: } \\
\text { - } \quad \text { La adquisición de competencias instrumenta- } \\
\text { les para el funcionamiento en el entorno } \\
\text { - Al refuerzo de la incorporación de contenidos } \\
\text { de la formación reglada y no reglada }\end{array}$ & $\begin{array}{l}\text { a) Niños y niñas } \\
\text { b) Adolescentes } \\
\text { c) Adultos }\end{array}$ \\
\hline $\begin{array}{l}\text { Funcionalidad y ocio } \\
\text { / tiempo libre }\end{array}$ & $\begin{array}{l}\text { a) Realización de adaptaciones para propiciar la } \\
\text { autonomía } \\
\text { b) Actividades de ocio cotidiano } \\
\text { c) Talleres comunitarios en actividades de ocio } \\
\text { normalizado } \\
\text { d) Cursos de formación } \\
\text { e) Viajes enmarcados en ocio normalizado }\end{array}$ & $\begin{array}{l}\text { a) Adolescentes } \\
\text { b) Adultos }\end{array}$ \\
\hline Trabajo & $\begin{array}{l}\text { a) Formación prelaboral } \\
\text { b) Prácticas no remuneradas en el interior de la } \\
\text { propia entidad o intermediadas con organizaciones } \\
\text { colaboradoras } \\
\text { c) Intermediación laboral remunerada con organi- } \\
\text { zaciones colaboradoras }\end{array}$ & a) Adultos \\
\hline Vida independiente & $\begin{array}{l}\text { - a) Inserción en una vivienda compartida con } \\
\text { apoyo que propicie: } \\
\text { - } \quad \text { La emancipación familiar y social de la persona } \\
\text { - } \quad \text { El desarrollo de las capacidades necesarias } \\
\text { para la vida independiente, tanto en la vivienda } \\
\text { como en el entorno } \\
\text { - La adquisición de habilidades sociales } \\
\text { - La toma de conciencia y el desarrollo de hábi- } \\
\text { tos de vida saludable }\end{array}$ & a) Adultos \\
\hline
\end{tabular}

Fuente: elaboración propia a partir de Andrade (21)

Así, tomando como referencia esta oferta de prestaciones de las cuales forman parte los sujetos de intervención de la entidad, se exponen a continuación los resultados de este trabajo, diferenciados en torno a los momentos en que se ha llevado a cabo: en primer lugar, exponiendo los resultados provenientes del subestudio cualitativo con base en revisión documental y realización de entrevistas y, seguidamente, los resultados provenientes del momento dos, a los cuales se ha arribado integrando una indagación cualitativa con entrevistas grupales con la aplicación de la herramienta cuantitativa AHP.
Resultados del primer momento: hallazgos cualitativos con base en revisión documental y entrevistas en profundidad

Reconociendo la interacción que se produce entre las características propias de la persona con discapacidad mental, por un lado, y las condiciones medioambientales, por otro, Cecap promueve desde su discurso y práctica institucional, la noción de especificidad (12), buscando satisfacer, en primer lugar, la necesidad de ver a la persona con discapacidad mental como alguien diferenciado, particular 
e individualizado (11), iniciando así un camino que busca dejar atrás nominaciones asociadas en algunos contextos, a adjetivaciones con carácter peyorativo, como las referidas a "discapacitado" o "disminuido" - por señalar algunas-, las cuales tienden a estar relacionadas con la idea de personas "sin capacidades", o con "menores capacidades", para reconocer a las personas con discapacidad mental, como sujetos de derechos con características específicas, individualizadas, diferenciadas y complementarias a las de otros agentes sociales.

En este sentido, hablar de especificidad, desde lo que emana de las reflexiones de los actores vinculados a la entidad, implica entender este concepto como la diferencia o el conjunto de particularidades que hacen que una persona sea única y diferenciada. Se incorpora, en este sentido, al conjunto de características físicas, sensoriales, emocionales y cognitivas que pueden ser vistas como fortalezas para el desenvolvimiento de la persona, pero también incorpora dentro de estas particularidades, a la sumatoria de rasgos que podrían entenderse como obstaculizadores para su desenvolvimiento en el marco de un determinado proyecto de vida.

En la tabla 2 se presentan algunas reflexiones que emergen desde diferentes actores vinculados a la intervención de Cecap, al hablar sobre los elementos asociados a la noción de especificidad.

TABLA 2. SELECCIÓN DE ALGUNAS REFLEXIONES DE LOS ACTORES AL HABLAR DE ESPECIFICIDAD

Todo el mundo tenemos una cualidad y tenemos un fallo, unos de lo que sea, unos porque son Síndrome de Down, unos porque en un accidente se les ha quedado paralizado el lado derecho o el lado izquierdo: gente normal, nada más que en la cabeza tienen algo que no les deja dormir o lo que sea, pero todo el mundo tiene algo que les falla, se les note o no se les note, pero todo el mundo tiene algo. (Sujeto de intervención de Cecap)

Para mí "especificidad" es lo que somos cada uno de nosotros: yo soy una persona diferente a cada uno de vosotros, tengo mis "especificidades": mis cualidades, mis características, eso es la "especificidad": soy única, y además pienso que cada uno de nosotros tenemos una parte bonita, una parte agradable, y otra parte negativa, y que podemos beneficiarnos todos de esas diferencias que hay en cada uno de nosotros porque somos únicos. (Madre de sujeto de intervención de Cecap)

Prefiero “especificidad" a Discapacidad, porque suena diferente, no sé lo que es, pero suena más agradable. (Sujeto de intervención de Cecap)

Cuando hablamos de Discapacidad, hablamos de que falta algo, tiene una connotación negativa [...] "especificidad", sin embargo habla de que cada persona somos un mundo, todos tenemos nuestras limitaciones, todos tenemos nuestros puntos fuertes [...] Cuando hablamos de Discapacidad, hablamos de exclusión, sin embargo, en la "especificidad" no, "especificidad" de lo que habla, es de que tú eres dueño de tu propio destino, porque eres una persona especial: eres tú [...] Sin embargo, Discapacidad suena a una persona a la cual los demás le tienen que hacer las cosas porque no es capaz. (Padre de sujeto de intervención de Cecap)

La "especificidad" no está hablando en ningún momento de que haya algo negativo, ni falta de capacidad, simplemente te habla de eso, de que cada uno es irrepetible, es único, y que por tanto, el conocimiento de esa singularidad es lo que nos da las claves para que cada persona pueda avanzar en su desarrollo personal, en su inclusión social, y en definitiva, en la consecución de los retos que como persona se tenga marcados. (Representante del Servicio de Atención a Personas con Discapacidad, Consejería de Salud y Bienestar Social)

[Desde la "especificidad"] tienes la capacidad para hacer todo lo que te propongas, como los otros chicos, como los "normales", Síndrome de Down, todo tipo de personas. (Sujeto de intervención de Cecap)

Cuando estamos hablando de una persona con discapacidad estamos hablando de una persona que "no puede", que tiene sus capacidades mermadas, entonces cuando hablamos de "especificidad", estamos hablando de cuáles son sus puntos fuertes, estamos empezando a fijarnos en qué tiene fuerte y en qué tiene débil, para poder apoyarnos en los puntos fuertes y sacar a flote los débiles y que esa persona pueda avanzar, en vez de dejarla estancada desde el punto de vista de que "no puede" [...] además, cuando se piensa que una persona no puede, se la deja ahí, un poco como abandonada, se deja de creer en su capacidad. (Director de unidad) 
A su vez, desde la especificidad, Cecap persigue la expansión de las posibilidades de inclusión social de las personas con discapacidad mental, en tanto, al reconocerlas con características específicas y diferenciadas, tal como en el caso de una persona sin discapacidad, se facilitaría la disminución progresiva - desde una mirada al componente medioambiental de la discapacidad - de las barreras de acceso a la estructura de oportunidades que la sociedad provee.

Por su parte, cabe relevar que la noción conceptual de especificidad, comprende principios constitutivos que se reconocen y promueven en el marco de la intervención que desarrolla Cecap. Estos se presentan en la figura 1.

En este contexto, los principios que constituyen la noción de especificidad representan en sí mismos, lineamientos relacionados y no excluyentes respecto a las prestaciones que se desarrollan desde la entidad para y con las personas con discapacidad mental.

Así, poniendo en el centro a un sujeto con características específicas, se busca desde Cecap $(11,12)$ que a través del diseño e implementación de las prestaciones, se propicie el que este se reconozca como una persona individualiza$d a$, singular, diferenciada y con aportes para

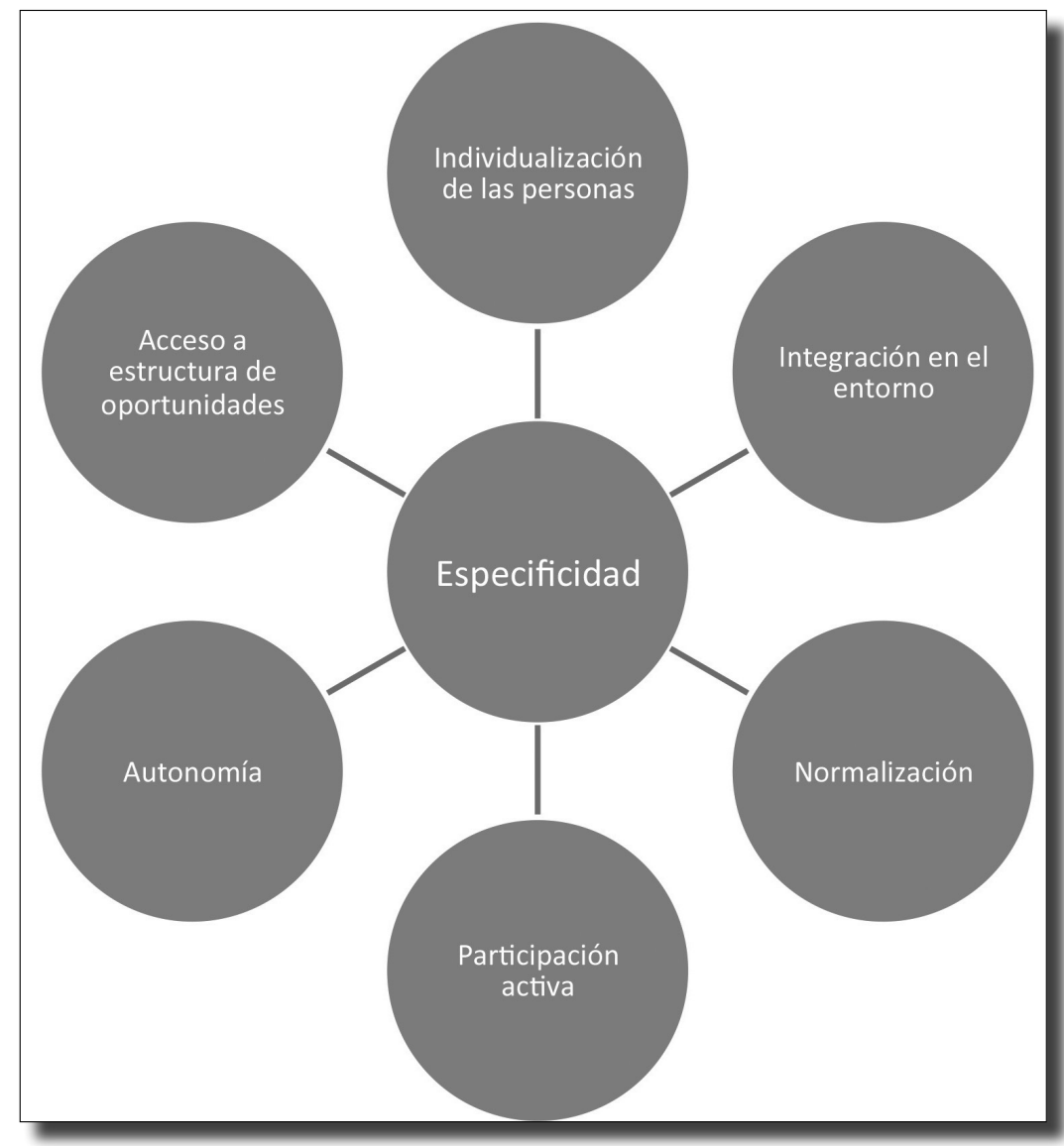

Figura 1. Principios constitutivos de la noción conceptual de "especificidad" Fuente: Andrade (21) 
entregar a la sociedad; asimismo, el que se integre progresivamente en el entorno, partiendo de su contexto inmediato. Por su parte, se persigue que esta integración no se realice exclusivamente en el marco de una intervención social, sino que pueda avanzar sostenidamente y, conforme las posibilidades de cada persona, a una inclusión normalizada, como en el caso de las personas sin discapacidad.

Ello, a su vez, promoviendo una participación activa de la persona con discapacidad mental, partiendo desde su entorno inmediato como puede ser el propio hogar de la persona, en el que, en algunos casos, debido a prácticas de sobreprotección de parte de sus familiares, se les ha obstaculizado el poder avanzar en la expansión de sus propias capacidades.

En este sentido, lo que se promueve es el tránsito hacia la máxima autonomía, de manera de poder, con los apoyos necesarios, tener acceso al más amplio abanico de posibilidades que se encuentran distribuidas en la estructura de oportunidades que proveen tanto el Estado como el mercado y la sociedad civil.

En esta línea, estos principios constitutivos de la noción de especificidad se constituyen como una matriz orientadora de la acción de la entidad, que es incorporada en cada una de las intervenciones que constituyen su oferta y que es operacionalizada transversalmente en el diseño de su modelo, por medio de sus componentes y subcomponentes específicos de hacer intervención social para y con el colectivo.

Hallazgos del segundo momento con base en aproximación cualitativa desde entrevistas grupales y la aplicación de la herramienta cuantitativa AHP

Elementos que conforman el modelo de intervención de la entidad. A continuación se presenta cada uno de los componentes del modelo de intervención social de Cecap, así como los subcomponentes que cada uno tiene asociado, y que representan, en conjunto, elementos que es necesario considerar en las iniciativas de intervención que realiza la entidad, con independencia del ámbito del bienestar en el cual se enmarque (tabla 1). Asimismo, en la figura 2 se presentan reunidos en una estructura jerárquica que los expone como modelo global en función del objetivo de inclusión para, en la tabla 3, presentar de manera sintética el detalle de prioridades que cada elemento tiene en el propósito de inclusión de sujetos con discapacidad mental.

Cabe relevar que, en diálogo con la noción de especificidad que promueve la entidad, cada uno de los elementos constitutivos de su diseño de intervención, se moviliza tomando en consideración las características específicas y diferenciadas de cada sujeto, poniéndose al servicio de su objetivo de inclusión social, el cual se pretende que sea explicitado desde la propia persona con discapacidad mental, conforme al máximo de sus posibilidades o, de ser el caso, sus familiares o adultos responsables, en las situaciones en que el sujeto no pueda hacerlo por sí mismo.

\section{Componentes del modelo de intervención de Cecap}

Componente 1: intermediación. Este componente se entiende como la dinamización que se desarrolla tanto con la oferta pública como con la privada, y en los niveles institucionales y comunitarios, en pos de la movilización de activos y recursos técnicos, económicos y sociales, que contribuyan al alcance de los objetivos de inclusión social de la persona con discapacidad mental.

En este contexto, la intermediación responde a toda acción que permita endogenizar re- 
cursos presentes en el medio, en pos de los objetivos de inclusión del sujeto.

Así, la intermediación opera, en primer lugar, en la lógica de visibilización o "mapeo" de la estructura de oportunidades y, segundo, sobre el desarrollo de acciones de dinamización o movilización de aquellos recursos que, en diálogo con el objetivo que se haya planteado la persona con discapacidad mental o, de ser el caso, sus familiares o adultos responsables, contribuyan a facilitar su plena inclusión en la sociedad.

Dentro de este marco, si bien la intermediación supone en escenarios eventuales articularse con diversos actores, la relación que se establece con ellos no se constituye en un vínculo permanente para el desarrollo de la intervención.

\section{Componente intermediación-subcomponentes}

Subcomponente 1: intermediación Institucional. La intermediación, desde su nivel institucional, se entiende como la intervención que se desarrolla con la oferta pública y privada, en pos de la identificación y movilización de los recursos que se pueden poner al servicio de las personas con discapacidad mental, a la luz de su objetivo de inclusión social. Ejemplo de esta intermediación, es la visibilización y movilización de la oferta de políticas y servicios sociales como acceso preferente a prestaciones de salud, o a regularización de estudios, o de capacitación laboral, por señalar algunas. Por su parte, es ejemplo de este tipo de intermediación institucional, toda identificación y movilización de recursos desde el sector empresarial o de la sociedad civil. A saber: cursos extraprogramáticos de formación no reglada; líneas de responsabilidad social que promuevan el acceso a ayudas técnicas; participación en actividades que promuevan el desarrollo de la persona; acceso preferente a iniciativas desarrolladas desde la sociedad civil como programas de inserción laboral, o de facilitación de acceso a la vivienda independiente, entre otras.

\section{Subcomponente 2: intermediación comu-}

nitaria. La intermediación, desde su nivel comunitario, se entiende como toda acción desarrollada desde los entornos inmediatos o próximos a la persona con discapacidad mental y que, sin formar parte de iniciativas formalizadas de políticas o programas específicos de la oferta pública o privada, contribuyen a avanzar hacia la inclusión social del sujeto. Se sitúa en este tipo de intermediación, toda identificación y dinamización de espacios de participación a la que puede acceder la persona con discapacidad mental, por ejemplo, en interior de una iglesia, o dentro de un gimnasio, o en el marco de actividades que desarrollan organizaciones sociales presentes en su entorno comunitario, por señalar algunas.

Componente 2: red de apoyo. La conformación y fortalecimiento de una red facilitadora que opere como un corresponsable en pos del objetivo de inclusión social de la persona con discapacidad mental, es un componente presente en el modelo de intervención de la entidad. Ello, en tanto se entiende que la inclusión del sujeto requiere la colaboración de otros que lo faciliten.

En este contexto, la red de apoyo se encuentra conformada, por un lado, por la familia directa o los adultos responsables de la persona con discapacidad mental; y, por otro, por las organizaciones colaboradoras con las que se establecen objetivos conjuntos de cooperación en pos de la plena inclusión social del sujeto y que representan, en sí mismos, facilitadores o socios estratégicos para la implementación de la intervención que se desarrolla. 
En esta línea, y a diferencia de las acciones llevadas a cabo a partir del componente de intermediación, la red de apoyo se entiende desde el vínculo que se genera entre la organización y un conjunto de actores que se configuran como corresponsables directos, en torno al objetivo de inclusión de la persona con discapacidad mental. Ello, por vía del establecimiento de un acuerdo de cooperación formal que ponga por encima dicho propósito.

Componente red de apoyo - Subcomponentes

\section{Sub componente 1: familia o adultos respon-} sables. La participación de la familia o, en su ausencia, de los adultos responsables de la persona con discapacidad mental, es un elemento presente en el modelo de intervención. En este contexto, su involucramiento activo en torno a los objetivos de la persona, desde el ejercicio de su rol de corresponsable directo, es un capital que se incorpora a la intervención, y al cual se le asiste técnicamente desde Cecap, por medio de la formación y la entrega de herramientas teóricas y prácticas, de modo de facilitar su ejercicio como un activo transversal, en pos de la consecución del objetivo de inclusión del sujeto.

\section{Sub componente 2: organización colaborado-}

ra. La participación de otros agentes corresponsables en torno al alcance de la inclusión de la persona, es un subcomponente presente dentro de la red de apoyo.

En este sentido, la participación activa, por ejemplo, de la escuela, en el caso de las intervenciones del ámbito educativo, así como también de los otros colaboradores con que se implementa la intervención, en los diferentes ámbitos del bienestar en los que se interviene (tabla 1), se constituyen en actores relevantes, con los cuales se formaliza una alianza en torno a los roles que ejercer tanto desde Cecap, como desde la propia organización colaboradora, en pos de la plena inclusión del sujeto con discapacidad mental.

\section{Componente 3: capacitación en competencias}

La capacitación se entiende como la acción de desarrollar y fortalecer competencias funcionales e intelectuales en la persona con discapacidad mental, con el fin de que esta pueda, conforme a sus recursos cognitivos, físicos, sensoriales y emocionales, afrontar las exigencias del entorno normalizado.

En este sentido, la capacitación se refiere a la idea de habilitar a la persona en competencias que le permitan un funcionamiento óptimo, en la lógica de habilitación para la vida en general, ya sea que deba funcionar de forma individual o entre pares, así como también, hace referencia a la habilitación y refuerzo de estrategias que promuevan el óptimo funcionamiento de procesos cognitivos de orden superior, y a la entrega de conocimientos específicos como lectoescritura $\mathrm{u}$ operaciones matemáticas, entre otros, que contribuyan, conforme al máximo de sus posibilidades, a su óptimo desenvolvimiento en el entorno.

\section{Componente capacitación en competencias - subcomponentes}

\section{Subcomponente 1: funcionales individuales.} Este subcomponente hace referencia a la capacitación que se realiza con el sujeto, de modo de contribuir a su funcionamiento en el entorno normalizado, por medio de la transferencia repetida de ejercicios que faciliten su funcionamiento en actividades individuales y personales, como por ejemplo vestirse, asearse, tomar las cosas que requiere en el interior de su hogar, entre otras, que constituyen el funcionamiento individualizado de la persona. 
Sub componente 2: relación entre pares. Este subcomponente de la capacitación alude a la transferencia repetida de ejercicios que propician un óptimo desenvolvimiento de la persona con discapacidad mental en entornos normalizados, a nivel de relación entre pares, con y sin discapacidad. Se incorpora en este tipo de capacitación, la trasferencia de herramientas que le permitan al sujeto saludar a otros, establecer conversaciones, pedir ayuda en los casos necesarios, entre otros vinculados al funcionamiento normalizado entre pares.

Sub componente 3: intelectuales. Este subcomponente hace referencia a la estimulación y el desarrollo repetido de ejercicios que fortalecen procesos cognitivos de orden superior, como la atención, el refuerzo de la memoria y la motivación, y que deben trabajarse de manera permanente, para facilitar la incorporación de otros aprendizajes en la persona con discapacidad mental.

Sub componente 4: instrumentales. La capacitación en competencias instrumentales se refiere al desarrollo y fortalecimiento de capacidades específicas como lectoescritura o lógica matemática, que le permitan al sujeto, conforme a sus posibilidades, realizar actividades como la redacción de una carta o de su currículum vitae, la lectura del número del autobus que requiere tomar, o el cálculo de operaciones matemáticas en el contexto de una compra, entre otras, relativas al funcionamiento en el entorno normalizado.

\section{Componente 4: Plan Individual de Intervención}

Como componente de un modelo de intervención orientado por la especificidad de la persona, el objetivo de inclusión que esta se traza, o en los casos necesarios, sus familiares o adultos responsables, debe responder

114 a la individualización y singularidad propia con la que ella cuenta. En este sentido, el objetivo que se busca alcanzar es registrado en lo que se conoce como el Plan Individual de Intervención (en adelante, llamado indistintamente como el Plan), el cual incorpora, así como su diagnóstico, cada una de las estrategias y apoyos únicos que se han de movilizar en torno al cumplimiento del objetivo de inclusión.

Para ello, la elaboración del Plan incorpora, por un lado, el diseño de un panel de especificidad, que condensa las particularidades del sujeto en torno a la identificación de los recursos individuales presentes en él, en contraste con la identificación de aquellos que pueden ejercer como potenciales limitantes de su plena inclusión. A su vez, el Plan Individual de Intervención incorpora la utilización del entorno normalizado como elemento presente en las acciones que es preciso trabajar en pos de la inclusión del sujeto.

\section{Componente Plan Individual de Intervención - subcomponentes}

Subcomponente 1: paneles de especificidad. Este subcomponente se entiende como el instrumento formalizado que sistematiza el objetivo de inclusión y el diagnóstico de la situación inicial de la persona en el momento de iniciar el proceso de intervención y que facilita el registrar los avances que esta presenta en torno a este objetivo. El panel de especificidad reúne, por un lado, la identificación de los recursos o puntos fuertes en los planos cognitivos, físicos, sensoriales y emocionales de la persona, y que pueden, con base en la estimulación adecuada, capitalizarse y convertirse en recursos facilitadores para su plena inclusión en términos de acceder y hacer uso de la estructura de oportunidades que la sociedad provee, enfrentando las exigencias del medio real.

Por su parte, el Panel de Especificidad identifica igualmente en los planos cognitivo, físico, 
sensorial y emocional, los puntos débiles o potenciales elementos limitantes de la inclusión de la persona, y que en el marco del Plan Individual de Intervención se constituyen en aspectos sobre los cuales diseñar estrategias reparatorias $\mathrm{o}$, a lo menos mitigantes, con el objeto de que puedan ejercer al mínimo como elementos obstaculizadores de su plena inclusión social.

Subcomponente 2: entorno normalizado. Este subcomponente se entiende como la utilización del entorno normalizado para el desarrollo de actividades en el marco del Plan Individual de Intervención de la persona. En este sentido, si bien la intervención reúne instancias formativas de desarrollo y fortalecimiento de competencias en aula, incorpora como elemento activo, instancias de formación que, de acuerdo con el objetivo de la persona, consideren la utilización del entorno normalizado como medio para dinamizar procesos de adquisición, interiorización y generalización de aprendizajes.

Componente 5: sensibilización social. La promoción del respeto a la diferencia y a la dignidad inherente de la persona con discapacidad mental, a su autonomía, a su independencia, así como a la libertad con la que cuenta para tomar, en diálogo con sus posibilidades, sus propias decisiones, en un marco de ejercicio de derechos desde una inclusión plena, y en igualdad de condiciones que los demás, requiere la permeabilidad de las dinámicas sociales que han, en determinados contextos, reproducido prácticas de exclusión hacia el colectivo.

En esta línea, este componente se entiende como todas aquellas acciones que se realizan desde el modelo de intervención de Cecap, tanto a nivel de campañas que promuevan la difusión de los derechos de las personas con discapacidad mental; a nivel de actividades participativas de integración entre personas con y sin discapacidad; a nivel de acciones de transferencia no formal de conocimiento relativo a la realidad que enfrentan; así como también, a nivel de actividades de visibilización del colectivo en entornos normalizados, sin la necesaria mediación directa entre el interventor y las personas sin discapacidad, y que en su conjunto, contribuyen a la disminución de las barreras de acceso a las que, en determinados contextos y momentos históricos, se han visto enfrentadas la personas con discapacidad mental.

\section{Componente de Sensibilización social - subcomponentes}

Subcomponente 1: campañas. Este subcomponente se entiende como las acciones de difusión y sensibilización en materia de los derechos de las personas con discapacidad mental que contribuyen a la eliminación de las barreras de acceso, a través de campañas en medios de comunicación escritos, televisivos, radiales, por medio de plataformas web, o a través de charlas a la comunidad, y que apuntan a la promoción del respeto, resguardo y a la restitución de los derechos de los sujetos con discapacidad mental.

Subcomponente 2: actividades participativas. Este subcomponente se entiende como las acciones de difusión y sensibilización en materia de los derechos de las personas con discapacidad mental que apuntan a la eliminación de las barreras de acceso, por medio de la realización de actividades participativas de integración entre personas con y sin discapacidad, buscando la disminución de las brechas entre dinámicas de relación tradicionalmente verticales, apuntando a la horizontalidad en las formas de acercamiento e integración entre personas con y sin discapacidad, con base en la utilización conjunta de diversos espacios participativos en entornos normalizados. 
Sub componente 3: transferencia no formal de conocimiento. La transferencia no formal de conocimiento se refiere a todas aquellas acciones de sensibilización directa en espacios no formales, en los cuales se transfiere información a los agentes sociales, que contribuya a la disminución de las barreras de acceso que ha enfrentado, en determinados contextos, el colectivo. Se sitúan en este subcomponente de la sensibilización social, todas aquellas conversaciones generadas en instancias no formalizadas, en las cuales se transfiere conocimiento relativo a los derechos de las personas con discapacidad mental, contribuyendo a su promoción, resguardo y restitución.

\section{Subcomponente 4: Visibilización no media-}

da. El subcomponente de visibilización no mediada se entiende como aquellas acciones de sensibilización "pasiva" que se realiza hacia los agentes sociales. En este sentido, se refiere a la acción de propiciar la disminución de las barreras de acceso, por medio de la

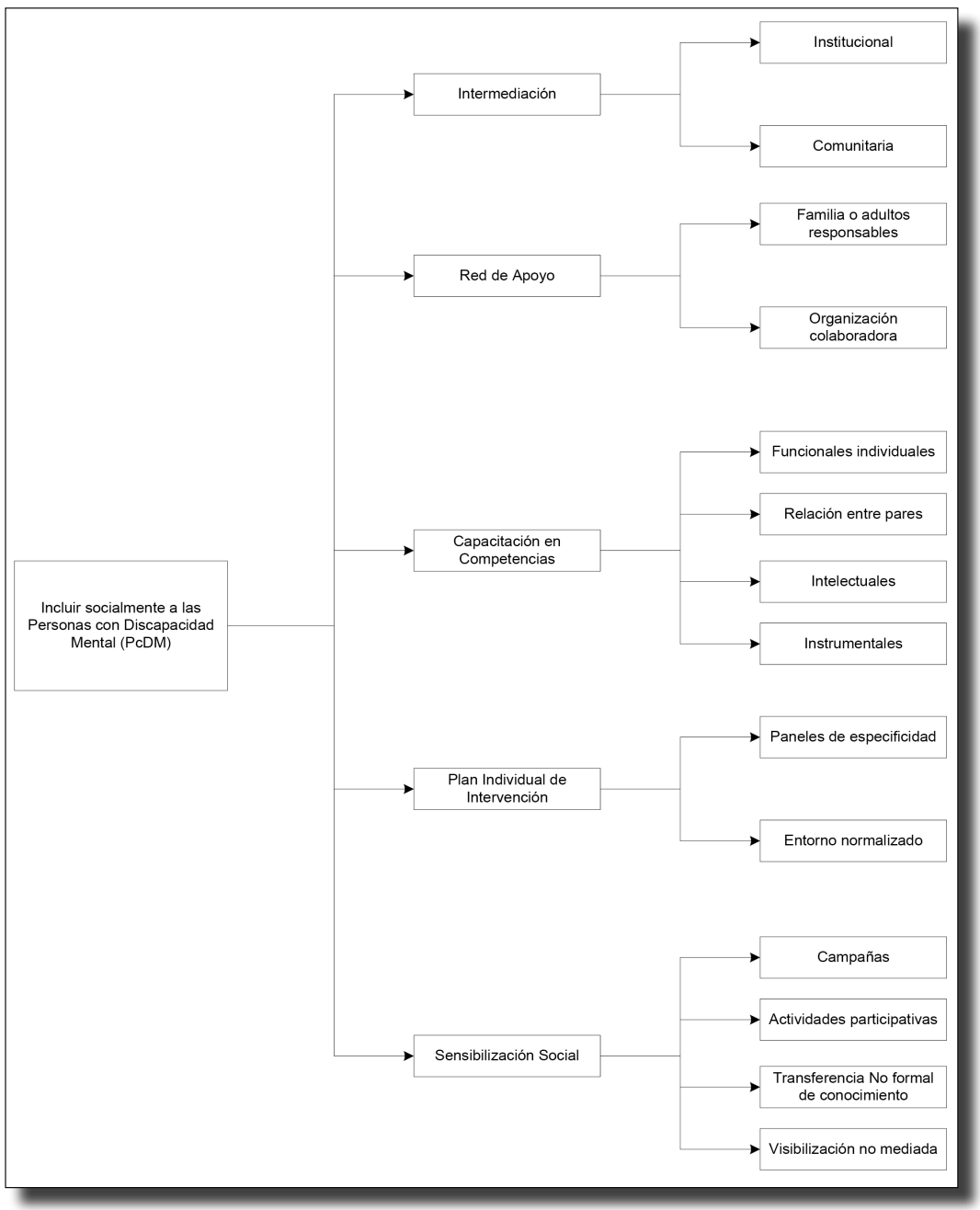

Figura 2. ESTRUCTURA JERÁRQUiCA: COMPONENTES Y SUBCOMPONENTES DEL MODELO DE INTERVENCIÓN SOCIAL

Fuente: elaboración propia 
ocupación de entornos normalizados, sin que se requiera la transferencia de conocimiento de la realidad que enfrenta el colectivo hacia la comunidad, sino sosteniendo acciones que contribuyan a su sola visibilización en espacios tradicionalmente utilizados por personas sin discapacidad mental.

Análisis de las prioridades de los componentes metodológicos en torno a la inclusión social del colectivo

Al analizar los cinco componentes que constituyen el modelo de intervención de la entidad, revisando la relevancia que cada uno de ellos reviste en el objetivo de incluir socialmente a la persona con discapacidad mental, el que presenta la más alta prioridad, es el referido al "Plan Individual de Intervención", con un 41,4\%. En este contexto, el desarrollar una intervención que reconozca las características específicas y diferenciadas con que cuenta cada sujeto, es un elemento gravitante a la hora de apuntar a su plena inclusión en el escenario social (ver tabla 3 ).

Así, desde la entidad, el desarrollar una estrategia de intervención basada en la individualidad de la persona, respondiendo a sus propios intereses, y adecuándola a sus cualidades, competencias, habilidades y destrezas, resulta prioritario para avanzar en la consecución del objetivo de plena inclusión.

En segundo orden de prioridad, le sigue el componente de "Capacitación de competencias", con un $26,10 \%$, el cual se vincula directamente con la necesidad de habilitar al sujeto para que pueda, conforme a sus recursos cognitivos, físicos, sensoriales y emocionales, afrontar las exigencias del entorno normalizado.

A su vez, en tercer lugar de prioridad, se sitúa el componente "Red de apoyo" (17\%).

TABLA 3. Prioridad de los componentes y subcomponentes del modelo de intervención de Cecap en la INCLUSIÓN SOCIAL DE LA PERSONA CON DISCAPACIDAD MENTAL

\begin{tabular}{|c|c|c|c|}
\hline Componente de intervención & $\begin{array}{l}\text { Prioridad para la } \\
\text { inclusión social }\end{array}$ & Subcomponente de intervención & $\begin{array}{l}\text { Prioridad para la } \\
\text { inclusión social }\end{array}$ \\
\hline \multirow{2}{*}{ Intermediación } & \multirow{2}{*}{$8,20 \%$} & Institucional & $38,90 \%$ \\
\hline & & Comunitaria & $61,10 \%$ \\
\hline \multirow{2}{*}{ Red de apoyo } & \multirow{2}{*}{$17,00 \%$} & Familia o adultos responsables & $53,50 \%$ \\
\hline & & Organización colaboradora & $46,50 \%$ \\
\hline \multirow{4}{*}{$\begin{array}{l}\text { Capacitación en competen- } \\
\text { cias }\end{array}$} & \multirow{4}{*}{$26,10 \%$} & Funcionales individuales & $17,50 \%$ \\
\hline & & Relación entre pares & $22,70 \%$ \\
\hline & & Intelectuales & $45,20 \%$ \\
\hline & & Instrumentales & $14,60 \%$ \\
\hline \multirow{2}{*}{$\begin{array}{l}\text { Plan Individual de Inter- } \\
\text { vención }\end{array}$} & \multirow{2}{*}{$41,40 \%$} & Paneles de Especificidad & $55,40 \%$ \\
\hline & & Entorno normalizado & $44,60 \%$ \\
\hline \multirow{4}{*}{ Sensibilización social } & \multirow{4}{*}{$7,20 \%$} & Campañas & $9,60 \%$ \\
\hline & & Actividades participativas & $45,40 \%$ \\
\hline & & $\begin{array}{l}\text { Transferencia no formal de cono- } \\
\text { cimiento }\end{array}$ & $27,40 \%$ \\
\hline & & Visibilización no mediada & $17,60 \%$ \\
\hline
\end{tabular}

Fuente: elaboración propia 
En este sentido, se reconoce desde Cecap la importancia de la Red, en términos de que se encuentre corresponsabilizada en torno a los objetivos que se persiguen para y con la persona con discapacidad mental, poniendo por encima el alcance de su objetivo de inclusión, en un marco de respeto de su proceso evolutivo y de las características de sus recursos personales que lo hacen único y diferenciado.

Con prioridades cercanas, se encuentran los componentes "Intermediación" y "Sensibilización Social", con un 8,2\% y un 7,2\%, respectivamente. Así, se aprecia que estos, contribuyendo igualmente a la inclusión social de la persona, lo hacen en menor medida, en relación con la importancia que reviste el diseñar una estrategia de intervención que reconozca las características específicas del sujeto, su habilitación para que pueda enfrentar las exigencias del entorno normalizado, y el capital que reviste el que la estrategia se conforme con actores corresponsabilizados y facilitadores en pos del objetivo que se persigue para y con la persona con discapacidad mental.

\section{Análisis por subcomponentes}

Componente intermediación. $\mathrm{Al}$ analizar las prioridades con que cuenta cada subcomponente de la "intermediación" en el objetivo de inclusión social, conforme a los datos que se presentan en la tabla 3 , la más alta recae en el subcomponente comunitario de la intervención, con un $61 \%$, versus un $39 \%$, el subcomponente institucional.

En este sentido, este porcentaje del subcomponente comunitario es alcanzado, en tanto por su cercanía inmediata a la persona con discapacidad mental, propiciaría de manera más efectiva en el corto plazo disminuir las barreras de inclusión que ha enfrentado en algunos casos el sujeto en su propio contexto.
Así, para la persona con discapacidad mental, su entorno cercano o comunitario, no es solamente aquel espacio conformado por sus familiares y/o adultos responsables, sino que también será entendido en función de las personas y organizaciones presentes en su contexto inmediato, y en los cuales la intervención de la entidad pone atención, de manera de facilitar la inclusión del sujeto.

Por su parte, el subcomponente institucional alcanza igualmente un porcentaje significativo de prioridad, en tanto es reconocido como relevante en la intervención, en términos de poder movilizar recursos presentes en la estructura de oportunidades y que pueden ponerse al servicio del objetivo de inclusión del sujeto.

Componente red de apoyo. En el marco del componente "Red de apoyo", el subcomponente "Familia o adultos responsables" alcanza la más alta prioridad, con un $54 \%$, en relación con el subcomponente "organización colaboradora", el cual cuenta con un $46 \%$ (véase tabla 3 ).

Dentro de este contexto, para Cecap las acciones que se desarrollen para robustecer el papel de corresponsable que tienen los primeros actores en el propósito de inclusión social del sujeto, cobra relevancia a la hora de pensar en prestaciones que se orienten por las características específicas de las personas con discapacidad mental.

Así, las estrategias que se desarrollan desde la entidad para apoyar este proceso con los familiares o adultos responsables, no privativamente cuando el sujeto es un niño o niña, sino que con independencia de la edad con la que este cuente, son elementos que se buscan y refuerzan de manera permanente desde las acciones que se desarrollan en el marco del objetivo de inclusión social de las personas con discapacidad que son sujetos de intervención. 
Por su parte, el trabajo con la organización colaboradora, se configura como un elemento igualmente relevante para la inclusión. En este sentido, para la entidad, las acciones que puedan desarrollarse para que los actores vinculados al sujeto en el marco de las prestaciones, por ejemplo, desde la empresa que lo contrata, en el contexto de una intervención del ámbito laboral, así como también, puede ser desde el colegio en el caso de una prestación del ámbito educativo - por señalar algunos casos de colaboradores-, refuercen su rol de corresponsables, revisten importancia para promover su inclusión, en tanto desde la propia entidad interventora, como desde los demás colaboradores, se dinamizan recursos que se ponen al servicio del objetivo de plena inclusión de la persona con discapacidad mental.

\section{Componente Capacitación en competencias.}

Con respecto a las prioridades con las que cuentan los subcomponentes de la "capacitación", es posible observar que la más alta prioridad para la inclusión social de la persona con discapacidad mental, la tiene la capacitación en competencias "intelectuales" $(45,2 \%)$. En este sentido, la intervención que se realiza desde Cecap con el sujeto, se orienta a la estimulación constante de las funciones cognitivas superiores, en tanto estas marcan el desarrollo y la ejecución de las distintas habilidades y destrezas necesarias para la inclusión de la persona con discapacidad mental.

En segundo orden de prioridad, se ubica la capacitación en competencias de "relación entre pares" $(22,7 \%)$, reconociendo desde la intervención, la importancia que reviste para alcanzar un escenario efectivo de inclusión, el que se potencien al máximo, todas aquellas áreas que permitan prospectar, al máximo de las posibilidades del sujeto, un escenario óptimo de relación ente personas con y sin discapacidad en entornos normalizados.
Le sigue, en tercer orden de prioridad, con un $17,5 \%$, la capacitación en competencias "funcionales individuales". Así, todas aquellas acciones presentes en la prestación que apunten al fortalecimiento del funcionamiento individualizado de la persona con discapacidad mental, promoviendo su autonomía en los planos personales, como por ejemplo: procurarse su aseo personal, vestirse, hacerse cargo de la preparación de sus alimentos, entre otras, se reconocen como relevantes desde la entidad, de manera de poder prospectar un escenario de inclusión social efectiva para el sujeto.

Finalmente, se ubica en cuarto lugar de prioridad, la capacitación de tipo "instrumental" $(14,6 \%)$, referida al desarrollo y fortalecimiento de capacidades como, por ejemplo, lectoescritura o lógica matemática, representando en sí mismos, aspectos en los que es necesario trabajar desde las acciones orientadas a favorecer la inclusión de la persona con discapacidad mental, en pos de un desenvolvimiento adecuado en entornos normalizados de desarrollo (véase tabla 3 ).

\section{Componente Plan Individual de Interven-}

ción. De acuerdo con los datos que entrega la tabla 3, la más alta prioridad en el componente "Plan Individual de Intervención" para la inclusión del sujeto, la presenta el "Panel de Especificidad", con un 55\%, en relación con el subcomponente "entorno normalizado", el cual cuenta con un $45 \%$. Así, se reconoce desde Cecap que esta brecha del $10 \%$ se explica porque ambos elementos presentan importancias relativamente similares en la intervención que se desarrolla para y con la persona con discapacidad mental, en pos de su plena inclusión. En este sentido, contar con un instrumento como el Panel de Especificidad, que permita recoger la sumatoria de características específicas de la persona, asî como hacer un seguimiento sistematizando los avances o retrocesos que en el proceso de 
inclusión se van presentando, en la línea de un sistema de monitoreo y control de gestión de la intervención, se vuelve un aspecto que se considera relevante a la hora de desarrollar las prestaciones.

Por su parte, el subcomponente "entorno normalizado" se reconoce igualmente como prioritario, en tanto las acciones que es preciso desarrollar, debiesen propender a la ocupación de la persona con discapacidad mental de espacios a los que, en algunos contextos, se han visto excluidos por su diagnóstico de salud, y en los cuales se pueden movilizar procesos de adquisición, interiorización y generalización de aprendizajes para su funcionamiento en un marco de plena inclusión.

Componente sensibilización. Las acciones de sensibilización que se desarrollan a partir de la intervención del Cecap para y con el sujeto, orientadas a resignificar las imágenes, valoraciones, los tipos de funcionamientos, así como también las formas en que se han tradicionalmente configurado los vínculos entre personas con y sin discapacidad, se desarrollan en la línea de que puedan ser progresivamente permeados, de manera de promover la disminución de barreras de acceso que, en determinados contextos, han enfrentado las personas con discapacidad mental.

Así, al observar las prioridades que alcanzan los subcomponentes de la "sensibilización" en el objetivo de inclusión (tabla 3), la más alta la alcanzan las actividades participativas, con un 45,4\%. En este sentido, se reconoce que estas sensibilizan desde la promoción del relacionamiento activo entre personas con y sin discapacidad, siendo un eje central que es necesario buscar desde las prestaciones, favoreciendo progresivamente el que desde estos espacios comunes de encuentro, se disminuyan las brechas de relacionamiento entre personas con y sin discapacidad. En este sentido, se promueve desde la entidad la realización, por ejemplo, de giras de excursión que integren a personas con y sin discapacidad, la realización de conciertos musicales que convoquen a ambos colectivos, el insertar a los sujetos en espacios laborales normalizados, entre otros, que brinden las posibilidades a las personas sin discapacidad, de relacionarse con personas que presentan alguna de tipo mental, favoreciendo su sensibilización y permanente toma de conciencia respecto a las capacidades, recursos y derechos con los que cuentan los sujetos con discapacidad mental para desenvolverse en el entorno normalizado.

En segundo orden de prioridad, se encuentra la transferencia no formal de conocimiento, con un $27,4 \%$, dando cuenta de que las iniciativas de inclusión que se desarrollen desde el modelo de intervención, deben estar acompañadas del permanente traspaso de experiencias en relación con las posibilidades y capacidades con que cuentan los sujetos, facilitando la promoción, restitución y resguardo de sus derechos, en un marco de inclusión social efectiva.

Con prioridades menores se encuentran tanto la visibilización no mediada, como las campañas, alcanzando prioridades de un $17,6 \%$ y un $9,6 \%$, respectivamente. Así, en el caso de la primera, se promueve desde la intervención de la entidad el que las personas con discapacidad hagan uso de espacios tradicionalmente utilizados por sujetos sin discapacidad, como pueden ser, por ejemplo, los centros comerciales, las librerías, los lugares de recreación, entre otros, sin la necesaria acción de los profesionales interventores, de manera que se intensifique la utilización de estos espacios normalizados, facilitando progresivamente su inclusión.

En el caso de las campañas, si bien se reconocen importantes, presentan la menor 
prioridad, principalmente porque se concibe, en términos generales, para los actores consultados el que ellas tienden a sensibilizar, mayoritariamente, a aquellos agentes que ya cuentan con un grado de sensibilidad previa respecto a la realidad que enfrentan las personas con discapacidad mental y otros colectivos vulnerables. En este sentido, teniendo en cuenta el que igualmente presentan una contribución al objetivo de inclusión social, desde la intervención de la entidad si bien se promueven, no se les asigna la más alta relevancia en relación con otras iniciativas que pueden desarrollarse para favorecer la inclusión del colectivo.

\section{Discusión}

Los resultados a los que se ha arribado desde la revisión de la experiencia de Cecap, tanto desde su propuesta conceptual de especificidad, como desde el modelo metodológico de intervención en el cual esta se operativiza, permiten recoger que su dispositivo dialoga con diversas aproximaciones que le asignan relevancia al contexto medioambiental como elemento relacionado de manera directa con el nivel de inclusión del colectivo de personas con discapacidad, presentando correlato con las propuestas que se recogen desde el modelo social, la CIF-OMs (20) y desde la propia Convención (2).

En este sentido, cabe recoger que para la entidad el hablar de avanzar hacia la plena inclusión del colectivo supone, por oposición, reconocer que en las distintas sociedades, en mayor o menor medida, se han presentado dinámicas de exclusión o distinción negativa hacia las personas que han presentado alguna discapacidad.

Dentro de este marco, la Convención (2) ha avanzado en términos de conceptualizar estas determinadas dinámicas, al explicitar en su artículo $2^{\mathrm{o}}$ lo que habrá de entenderse por "discriminación por motivos de discapacidad", aludiendo a que esta referirá a "cualquier distinción, exclusión o restricción por motivos de discapacidad que tenga el propósito o el efecto de obstaculizar o dejar sin efecto el reconocimiento, goce o ejercicio, en igualdad de condiciones, de todos los derechos humanos y libertades fundamentales" (2).

Por su parte, los resultados que presenta este trabajo, particularmente desde la observación del dispositivo metodológico de intervención de la entidad, dan cuenta de que las prioridades de los elementos componentes y subcomponentes del modelo de Cecap, en relación con la inclusión social del colectivo, encuentran un correlato con la discusión que sobre discapacidad y derechos, ha establecido la literatura especializada.

En este contexto, ha sido posible reconocer que el componente Plan Individual de Intervención presenta la más alta prioridad para la inclusión (41,4\%, conforme a los datos de la tabla 3), y en este marco, el trabajo con sus dos subcomponentes: panel de especificidad y la utilización del entorno normalizado, presentan ambos prioridades relevantes para el logro del objetivo (el primero un 55,4\%, mientras que el segundo un 44,6\%). Estos hallazgos permiten observar un diálogo con la importancia relevada desde la literatura en torno a la relación entre sujeto y contexto social para la intervención, por ejemplo, desde los trabajos de Anaut-Bravo, Urizarna y Verdugo (9) o de De Robertis (22).

En esta línea, esta última expone en relación con el contexto de intervención y los sujetos, que "las intervenciones en el entorno del usuario tienen como objetivo modificar su situación exterior, ampliar su inserción social y modificar la aptitud que tienen a su respecto las personas significativas que lo rodean" (22, 
p. 271), lo cual dialoga de manera directa con lo buscado desde la prestación de Cecap, a partir de diversos elementos de su modelo.

Por su parte, la propuesta conceptual y metodológica de la entidad, en tanto reconoce como principio de la especificidad, a la normalización, se acerca a lo que ha sido reconocido por la literatura especializada en discapacidad, principalmente desde la construcción de "representaciones" asociadas tradicionalmente al fenómeno. En este contexto, Fantova (23) advierte que normalizar se entiende en el sentido de garantizar que las personas tengan a su disposición los medios que en su entorno son valorados o deseados en general. Señala así que "el principio de normalización nos ayuda a hacernos conscientes de la importancia de las imágenes, valoraciones, funcionamientos y vínculos sociales en los procesos de desarrollo personal y colectivo" (23, p. 12).

En este sentido, así como la utilización, por ejemplo del entorno, las acciones de sensibilización que desarrolla Cecap en relación con actividades participativas, se inscriben en este trabajo de resignificación de imágenes, valoraciones, tipos de funcionamientos y de las formas en que se han tradicionalmente configurado los vínculos -o ausencia de ellos-entre personas con y sin discapacidad.

A su vez, elementos del dispositivo de intervención con alta prioridad para la inclusión y que entran en diálogo con aportes de la literatura especializada, son la capacitación en competencias $(26,10 \%)$ y la red de apoyo con la cual se desarrolla la intervención (17\%).

En este escenario, particularmente relevante en torno al componente de capacitación es reconocer cómo su subcomponente de capacitación en competencias intelectuales, presenta la más alta prioridad, con un $45,20 \%$. Ello, dialogando con la CIF-OMS
(20), que las reconoce como las funciones mentales generales necesarias para comprender e integrar de forma constructiva las diferentes funciones mentales, incluyendo todas aquellas funciones cognitivas y su desarrollo a lo largo del ciclo de vida, las que desde la intervención de Cecap se consideran como condiciones necesarias para el ejercicio activo de derechos desde un escenario de plena inclusión.

Por su parte, con base en el reconocimiento de otros elementos de intervención de Cecap que, en alguna medida, han sido visibilizados a través de la literatura especializada en la materia, se encuentra, en el marco de la red de apoyo, el trabajo con la familia, la cual para los actores constituye un 53,5\% de prioridad dentro del componente de red (tabla 3), en sintonía con las reflexiones que en materia del rol de la familia del sujeto con discapacidad establece Fantova (24), al señalar que esta:

[...] tendrá que ir reconstruyendo su mundo de sentido, para dar significado y valor a un acontecimiento y una presencia al que el entorno sociocultural normalmente no se lo da. También será necesario aprender a relacionarse y comunicarse con el familiar con discapacidad $[\ldots]$ para ello, padres y familiares tendrán que reaprender lenguajes olvidados o aprender o construir otros nuevos. En otras ocasiones habrá que aprender a manejar otro tipo de recursos: materiales, sociales. Recursos que, en muchas ocasiones, se desconocían por completo o se consideraban como de otro mundo. (24, p. 9)

Dialogando con lo anterior, el dispositivo de Cecap interviene desde la entrega de herramientas en pos de potenciar a la familia como un agente corresponsable con herramientas y recursos para facilitar la inclusión del sujeto con discapacidad mental. 
Dados los elementos expuestos, y en tanto la discapacidad, al ser observada desde un marco de derechos, supone una categoría social construida en la cual los entornos sociales tendrían una relevancia superlativa a la hora de explicar su magnitud (18), se establece el espacio para reflexionar permanentemente en materia de intervención, cuestionando y revisando los dispositivos, tanto desde sus nociones conceptuales, como desde su operacionalización y desarrollo en los espacios territoriales, por ejemplo, desde el cómo se ajustan para responder a las características múltiples y complejas de los entornos en los que es necesario intervenir para promover y resguardar la inclusión social de los sujetos con discapacidad mental.

\section{Conclusiones}

Este trabajo, con base en la observación en profundidad del caso de Cecap, ha buscado responder qué aprendizajes conceptuales pueden levantarse para las políticas e intervenciones sociales de discapacidad mental, así como también, desde una mirada metodológica, ha indagado sobre qué elementos componentes y subcomponentes de su modelo de intervención contribuyen mayormente al objetivo de plena inclusión del colectivo.

En este contexto, y desde un marco centrado en el enfoque de derechos, las políticas e intervenciones sociales de discapacidad mental, en tanto se sitúan en entornos sociales complejos, requieren revisar e innovar de manera permanente los dispositivos que se generan para promover la inclusión social del colectivo.

Así, en torno a la experiencia específica de Cecap, su propuesta conceptual y metodológica, siendo igualmente susceptible de permanente revisión de manera de ajustarse a las necesidades de los sujetos, presenta elementos que desde el enfoque de derechos apuntan directamente a la mejora de la calidad de vida del colectivo, desde el desarrollo de iniciativas de prestación que se centran en sus intereses y características particulares. En esta línea, van Loon (25) señala, en relación con discapacidad intelectual, elementos extensibles al caso de discapacidad mental:

[...] si se desea mejorar la calidad de vida de las personas, debe hacerse a través de los apoyos individualizados. La comunidad es el contexto de una vida de calidad: es esencial que las personas puedan participar en su comunidad. Por ello, los proveedores de servicios necesitan redefinir sus papeles como puentes hacia la comunidad. Además de proporcionar servicios a las personas con discapacidad intelectual es importante utilizar una planificación centrada en la persona, brindar apoyos individualizados e involucrar a los usuarios en la planificación y evaluación de los servicios proporcionados. $(25$, p. 42$)$

Así, Cecap y su intervención se inscriben de manera directa en estas recomendaciones, desarrollando estrategias centradas en los sujetos, las cuales se expresan en el Plan Individual de Intervención, el cual sirve de ancla entre el sujeto y el entorno desde y en el cual se busca su plena inclusión.

De este modo, entendiendo este plan y los elementos que lo conforman: panel de especificidad y entorno normalizado, como herramientas metodológicas, como tales deben ponerse siempre al servicio de los objetivos de inclusión que se plantee el propio sujeto, siendo lo suficientemente flexibles como para adaptarse a los diferentes propósitos que este persiga en función de sus intereses y de sus características específicas, reconociendo estas últimas como capitales claves para dinamizar en servicio de su inclusión. 
En este sentido, en términos de aprendizajes para las políticas e intervenciones, lo anterior supone que las iniciativas consideren estos elementos como pilares fundamentales de una medida centrada en derechos.

Así, particularmente relevante es recoger que las iniciativas de política e intervención que consideren este enfoque, deben necesariamente resguardar los mecanismos que posibiliten el reconocimiento de estos intereses y características particulares de cada sujeto, en acuerdo con los principios de la Convención como, por ejemplo, el de respeto a la diferencia señalado en su artículo $3^{3}$ (2).

De este modo, hablar de especificidad y hablar de enfoque de derechos constituye propuestas entrelazadas y complementarias para orientar las iniciativas que se dirijan al colectivo desde un acercamiento, puesto tanto en sus características específicas como en el reconocimiento que, en materia de plena inclusión, suponen los elementos medioambientales que promueven o dificultan este proceso. Ello, reconociéndose como una propuesta conceptual que puede iluminar las políticas e intervenciones que se orientan a otros colectivos con diagnósticos asociados a otro tipo de discapacidades - por ejemplo, de tipo sensorial一.

Por su parte, reconociendo esta complementariedad, se recoge como aprendizaje para las políticas e intervenciones, además, el que una propuesta conceptual y metodológica orientada por la especificidad, presenta posibilidades para incidir en la eliminación progresiva de las barreras de acceso que ha enfrentado el colectivo de sujetos con discapacidad mental en tanto sitúa a la persona en un umbral igualitario a la persona, sin un diagnóstico asociado a la discapacidad, al reconocer en la primera un conjunto de 124 características que la hacen única y específica, con independencia del diagnóstico que presente y de la diversidad de apoyos que se requieran para contribuir a su inclusión.

En este contexto, cabe relevar que el ver a la persona con discapacidad mental desde este conjunto de características que la entienden como única, particular y diferenciada del resto, también en este sentido, se hace cargo de que no todas cuentan de manera universal con el mismo nivel de desarrollo en cada uno de los planos físico, mental, sensorial o emocional, pudiendo existir personas con mayores o menores recursos en uno de estos ámbitos, pero pudiendo sobre la base de un trabajo focalizado desde las iniciativas de intervención contribuir, por un lado, al fortalecimiento de aquellos reconocidos como potenciales obstaculizadores de su inclusión y, por otro, a la potenciación de aquellos que mayormente puedan operar como facilitadores, de manera de posibilitar el que el sujeto con discapacidad mental se pueda posicionar en una mejor situación para llevar adelante su proyecto de vida.

En este marco cabe igualmente poner de relieve, en términos de aprendizajes, que hablar de especificidad o de personas con "especificidades", constituye simbólicamente un elemento de diferenciación relevante respecto a hablar de discapacidad, en tanto al primero se le asocia, de acuerdo con el conjunto de personas consultadas, con aspectos positivos como, por ejemplo, la propia individuación del sujeto, el reconocimiento de sus características específicas en términos de intereses y necesidades, así como con la visibilización del conjunto de los recursos con los que este cuenta de manera particular, entre otros aspectos que al estar asociados positivamente entre sí, facilitan el cambio progresivo en la forma de ver la discapacidad (o la "no capacidad"), propiciando el que se pueda partir de una base que promueva el rompimiento de prejuicios vinculados a que las personas con discapacidad mental "no 
pueden" hacer ciertas cosas, para instalar una concepción que facilite el entendimiento de que "sí pueden" hacer las tareas y las actividades que desean hacer, siempre en consonancia con esas características diferenciadas y únicas que la hacen ser una persona individual, singular e irrepetible, con derechos que ejercer en la sociedad.

En este sentido, lo anterior conlleva un desafío para las políticas e intervenciones sociales, en el sentido de continuar robusteciendo la estructura de oportunidades, de manera de que las personas con discapacidad mental que, en este caso, atiende la entidad, así como también el resto de sujetos que conforman el colectivo, puedan, en igualdad de condiciones que uno sin discapacidad, plantearse proyectos de vida sostenibles en un marco de ejercicio activo de derechos, siempre en diálogo con sus intereses, sus singularidades, sus competencias, y toda la sumatoria de características diferenciadas que la constituyen, así como a una persona sin discapacidad, en un sujeto con especificidades.

Ello, no obstante, implica necesariamente, el reconocer que las políticas e intervenciones sociales deben poner el acento, en algunos casos, en iniciar su trabajo desde la capacitación en competencias, en un nivel general, y de tipo intelectual, en un nivel específico, en pos de facilitar la instalación y el desarrollo de condiciones mínimas necesarias para que sean los propios sujetos con discapacidad mental, quienes se planteen sus objetivos o proyectos de vida en los distintos ámbitos del bienestar, propendiendo progresivamente a disminuir la práctica de que estos proyectos u objetivos sean planteados por sus familiares o adultos responsables, u otros actores relacionados con ellos.

Lo anterior, desde un reconocimiento y validación integral de sus necesidades e intereses que ponga a su servicio el conjunto de los recursos con los que cuentan las intervenciones, en la línea de lo que Ardón-Centeno y Cubillos-Novella reconocen para el caso de iniciativas en salud mental, como una "forma de organización de servicios" que esté en consonancia con, entre otros sentidos, la equidad social, la corresponsabilidad entre los diferentes actores, la solidaridad y la participación social (26).

Vinculado a lo anterior, desde la observación de Cecap, se recoge igualmente como aprendizaje el que las iniciativas que se orienten a la inclusión del colectivo, deben enfatizar en la corresponsabilidad, promoviendo y vinculando a diferentes actores, con especial énfasis en aquellos directamente relacionados con la persona, como pueden ser los familiares o adultos responsables. Ello, en la medida en que representan parte relevante del propio capital social del sujeto que se puede dinamizar en pos de su inclusión.

Para ello, no obstante, teniéndose en cuenta la importancia de generar dispositivos específicos de entrega de herramientas, como los que desarrolla Cecap en el marco del componente de red de apoyo, para que, en los casos necesarios, puedan estos actores reconocer en la persona con discapacidad mental a un sujeto con derechos, así como también puedan incorporar los conocimientos específicos para poder relacionarse con ellos, potenciar sus capacidades y facilitar su plena inclusión.

Lo anterior, es especialmente relevante ante los eventuales escenarios de sobreprotección o, en algunos casos, de infantilización que vive la persona con discapacidad mental, incluso en la edad adulta. En este marco, si se considera - por señalar un caso- que uno de los derechos que posee toda persona con discapacidad es a vivir de forma independiente y a ser incluido en la comunidad 
(según consagra la Convención su artículo 19), la preparación y el acompañamiento que pueda realizarse con la familia para que esta contribuya al pleno ejercicio de este y otros derechos, es un elemento central que considerar en las políticas e intervenciones.

Asimismo, otros aprendizajes de orden metodológico que se levantan para las iniciativas de discapacidad mental desde la revisión de Cecap, dicen relación con que estas deben promover de manera activa el desarrollo de actividades que vinculen a personas con y sin discapacidad mental, en distintos ámbitos de desarrollo. Ello, ya que se puede apuntar de esta manera a la eliminación de barreras de entrada, específicamente desde la promoción de la aceptación de la diferencia entre personas con y sin discapacidad mental.

Finalmente, el desafío se hace extensible para todos los actores sociales en torno a cómo se generan y resguardan condiciones de sostenibilidad, que permitan que las personas con discapacidad mental puedan materializar sus proyectos de vida, en un marco de inclusión social efectiva, permitiendo el que estos respondan a aquellos intereses individuales y singulares de personas únicas, diferenciadas e irrepetibles, con determinadas especificidades, como cualquier otro integrante de la sociedad.

\section{Referencias bibliográficas}

1. Comisión Europea. Comunicación de la comisión al Parlamento Europeo, al Consejo, al Comité Económico y Social Europeo y al Comité De Las Regiones. Estrategia europea sobre discapacidad 2010-2020: Un compromiso renovado para una Europa sin barreras. Bruselas, 2010 [Internet] [acceso: 15 de septiembre del 2014]. Disponible en: http://sid.usal.es/leyes/discapacidad/15833/3-3-7/ comunicacion-de-la-comision-al-parlamentoeuropeo-al-consejo-al-comite-economico-y-socialeuropeo-y-al-comite-de-las-regiones-estrategiaeuropea-sobre.aspx
2. Organización de las Naciones Unidas. Convención sobre los derechos de las personas con Discapacidad; 2006.

3. Consejo de Europa. Plan de acción para las personas con discapacidad 2006-2015. Un plan sobre cómo mejorar la vida de las personas con discapacidad en Europa; 2006.

4. España. Real Decreto Legislativo 1/2013, de 29 de noviembre, por el que se aprueba el Texto Refundido de la Ley General de derechos de las personas con discapacidad y de su inclusión social; 2013

5. España. Estrategia Española sobre Discapacidad 2012-2020; s/f.

6. Consejo de Europa. Comité de Ministros. Recomendación 5 del Comité de Ministros a los Estados miembros sobre el Plan de Acción del Consejo de Europa para la promoción de derechos y la plena participación de las personas con discapacidad en la sociedad: mejorar la calidad de vida de las personas con discapacidad en Europa 2006-2015; 2006.

7. Organización Mundial de la Salud (oms). Informe Mundial sobre la discapacidad; 2011.

8. Acuña C, Bulit L, Chudnovsky M, Repetto F. Discapacidad: derechos y políticas públicas. En: Acuña C, Bulit L, compiladores. Políticas sobre la discapacidad en la argentina: el desafío de hacer realidad los derechos. Argentina; 2010.

9. Anaut-Bravo S, Urizarna S, Verdugo M. Contexto social de la discapacidad. En: Diez E, Caparrós N, Britt G, coordinadoras. Atención social de personas con discapacidad: hacia un enfoque de derechos humanos. Argentina; 2012.

10. Valles M. Técnicas cualitativas de investigación social: Reflexión metodológica y práctica profesional. Madrid: Síntesis; 2000.

11. Servicio de Capacitación (Cecap). Dossier de intervención; s/f.

12. Servicio de Capacitación (Cecap). Protocolo de actuación; s/f.

13. Saaty T. Fundamentals of Decision Making and Priority Theory with the Analytic Hierarchy Process. Analytic Hierarcky Process Series. 1994; 6. Pittsburgh: Rws Publications.

14. Saaty T. Toma de decisiones para líderes: el proceso analítico jerárquico. La toma de decisiones en un mundo complejo. Pittsburg: Rws Publications; 1997.

15. Andreu J. Las técnicas de análisis de contenido: una revisión actualizada. España; s/f.

16. Palacios A. El modelo social de discapacidad: orígenes, caracterización y plasmación en la Convención Internacional sobre los Derechos de las Personas con Discapacidad. España: Cermi, Ediciones Cinca; 2008.

17. Martínez B. Pobreza, discapacidad y derechos humanos. Aproximación a los costes extraordinarios de la discapacidad y su contribución a la pobreza desde un enfoque basado en los derechos humanos. España: Cermi, Ediciones Cinca; 2011.

18. Díaz E. Reflexiones epistemológicas para una sociología de la discapacidad. Revista Sociológica de Pensamiento Crítico. 2009; 3(2).

19. Servicio Nacional de la Discapacidad (Senadis), Conferencia Episcopal de Chile y Universidad 
Católica Cardenal Silva Henríquez (UCSH). Rampas y barreras. Hacia una cultura de la inclusión de las personas con discapacidad. Santiago, Chile; 2010.

20. Organización Mundial de la Salud (oms). Clasificación internacional del funcionamiento, de la discapacidad y de la salud; 2001.

21. Andrade C. Reflexiones y aprendizajes a parir de intervenciones sociales con personas con discapacidad mental: El caso del Centro de Capacitación (Cecap) Toledo; 2010 [Internet] [acceso: $15 \mathrm{de}$ septiembre de 2014]. Disponible en: http://www. cecaptoledo.es/descargas

22. De Robertis C. Metodología de la intervención en trabajo social. Buenos Aires, Argentina: Grupo Editorial Lumen; 2006.

23. Fantova F. Exclusión e inclusión social: una aproximación desde el ámbito de la discapacidad.
Tercer Congreso Internacional de Discapacidad. Inclusión: oportunidades para todos. Instituto Los Álamos, Fundación Integrar, Medellín, Colombia; 2006.

24. Fantova F. Trabajar con las familias de las personas con discapacidades. Texto preparado para el Curso de Experto en Educación Especial de la Universidad de Deusto (octubre-noviembre de 2002); 2002.

25. Van Loon J. Un sistema de apoyos centrado en la persona. mejoras en la calidad de vida a través de los apoyos. En: Siglo Cero, Revista Española sobre Discapacidad Intelectual. 2009; 40 (229).

26. Ardón-Centeno N, Cubillos-Novella A. La salud mental: una mirada desde su evolución en la normatividad colombiana. 1960-2012. Revista Gerencia y Políticas de Salud. 2012; 11 (23): 12-38. Bogotá: Pontificia Universidad Javeriana. 